\title{
Persistence of frequency in gas-liquid flows across a change in pipe diameter or orientation
}

Barry J. Azzopardi, Amadi Ijioma ${ }^{1}$, Shounan Yang, Lokman A. Abdulkareem², Abdelwahid

$$
\text { Azzi }^{3}, \text { Mukhtar Abdulkadir }^{4}
$$

Faculty of Engineering, University of Nottingham, University Park, Nottingham, NG7 2RD, United Kingdom

1 current address: Department of Earth Sciences and Engineering, Imperial College, London SW7 2AZ, United Kingdom

2 current address: Petroleum Engineering, Faculty of Engineering, University of Zakho, Northern Iraq.

3 current address: Université des Sciences et de la Technologie Houari Boumediene, FGMGP, LTPMP, Bab-Ezzouar, 16111 Algiers, Algeria

4 current address: Department of Chemical Engineering, Federal University of Technology, PMB 65, Minna, Nigeria

Keywords: Sudden contraction, Venturi, bends, gas/liquid, void fraction, frequency, vertical, inclined, ECT

\section{ABSTRACT}

From a study of the characteristics of structures across a $67 / 38 \mathrm{~mm}$ sudden contraction, using air/silicone oil flows, it has been found that frequencies of the structures (mainly slugs) persist across the contraction. This is in contrast to the velocities and lengths which increase as they move in to the smaller diameter pipe. These observations were found for both vertical and $5^{\circ}$ upward orientations. A similar persistence of frequency has been found from four other sources in the literature: a vertical (gradual) contraction; a horizontal Venturi; and two cases of horizontal pipe, $90^{\circ}$ bend and vertical riser combination. The latter were at two contrasting conditions: (i) at atmospheric pressure with air/water in small diameter (34 mm) pipes; (ii) at 20 bar in larger diameter pipes (189 mm) using nitrogen and naphtha. 
Introduction

The upstream oil/gas production industry needs to calculate the flow rate/pressure drop/geometry relationships for complex piping systems as part of the design of production systems, particularly for offshore installations. In current methodologies, complex systems are divided into sections of constant diameter and orientation. The flow/pressure information is generated for this section, often by subdividing it into smaller axial steps. Where there are changes in pipe diameter, orientation, the additional pressure drop due to the fitting, i.e., the expansion, contraction or bend is then calculated before the next straight section of pipe is tackled. However, this ignores the transport of information through the system. This is clearest when the flow pattern is the same on both sides of the fitting. It has been most clearly illustrated by Saidj et al. (2014) who pointed out that, for same pipe diameter and flow rates, the frequency of slugs is found to be the same before and after the bend. This is significantly different from experiments with just straight pipes, where the gas and liquid are mixed at the entrance of the pipe. In those cases the slug frequency is much greater when the pipe is vertical than when it is horizontal.

Gas-liquid two-phase flow is probably the most common combination of phases in multiphase flow. Consequently, there has been much research in this area. There is strong interest from the part of the oil/gas industry engaged in extracting the oil and gas from reservoirs as well as from companies operating in oil refineries and hydrocarbon processing plant. In addition, there are also needs from the power generation industries (nuclear or fossil) and the chemical process industry (reboilers and condensers). The transport of gas-liquid flow plays a major role in their applications and clearly the ability to predict the fluid flow behaviour of these processes. Hence, research in this field of multiphase flow is very important from engineering and economical point of view to improve safety, reliability, sustainability, efficiency and significant decrease in frequency of maintenance multiphase flow equipment in for example the petroleum and 
chemical industry Azzopardi (2006). A persistent theme throughout the study of multiphase flow is the need to model and predict the detailed behaviour of those flows and phenomena that they manifest. There are three ways in which such models are explored: experimentally, through laboratory sized models equipped with appropriate instrumentation, theoretically using mathematical equations and models for flow and computationally using the power and size of modern computers to address the complexity of the flow, Brennen (2005). In many cases the laboratory model is of a different scale to the prototype, therefore a reliable theoretical model is essential for confident extrapolation to the scale of the prototype.

Various correlations and models for gas-liquid pressure drop across sudden contraction have been proposed by different authors. Chen et al. (2010) wrote a critical literature review carried out to compare popular pressure drop correlations. This included the homogenous pressure drop proposed by Collier and Thome (1976) and Chisholm (1983), momentum and mass transfer based correlation by Schmidt and Friedel (1997) and a mechanical energy equation model across the contraction. Their analysis showed that the homogenous model gave the best predictions when the pressure drops for steam-water mixture through a sudden contraction of different area ratios were measured. Attou and Bolle (1999) identified that most of the methods above do not take the flow pattern into consideration. They devised a pressure drop correlation which involves the balance equations deduced from macroscopic mass, momentum, entropy and energy conservation laws as well as a balance of forces exerted on the dispersed bubbles phases for bubbly flow. The model was found to be in good agreement with several experimental data of literature obtained for bubbly air-water flows through thick and thin orifice. However, it should be noted that pressure drop correlations used in thick orifices is a combination of that of sudden contraction and expansion. Correlations based on the two-phase singular pressure drop multiplier have been proposed by, e.g., Attou and Bolle (1997) and Fossa and Guglielmini (2002). These are functions of inlet void fraction of the dimensions of the 
fitting.

Fossa et al. (2006) studied the effect of different thickness of sharp edge orifice on an intermittent horizontal air-water gas-liquid flow by evaluating the local void fraction distribution downstream the orifice. The analysis showed that the void fraction usually reaches a maximum at a distance of about one diameter from the throat. Flow in the developing region and the developing length (downstream contraction) is also dependent on the upstream flow pattern and area ratio. Fossa and Guglielmini (2002) noted that this behaviour has been observed irrespective of the orifice thickness for higher values of liquid flow rate and even more evident when the area ratio is low.

The rise velocity of bullet shaped bubbles which occupy the greater part of the pipe cross-section was first studied analytically by Dumitrescu ( 1943) and Davis and Taylor (1950) who determined the rise velocity to have a value of $\operatorname{Fr} \sqrt{ }(g D)$, where $D$ is the pipe diameter. They proposed values of $F r$ of 0.351 and 0.328 respectively. There have been further studies since, the most comprehensive of which is that of Viana et al. (2003) who examined the effects of liquid viscosity, surface tension and pipe diameter on the Froude number. They present an equation for $\mathrm{Fr}$ based of the Eötvös number $\left(=g \rho_{l} D^{2} / \sigma\right)$ and a dimensionless inverse viscosity, which they term the gravity Reynolds number, $\left(=\sqrt{ }\left(g D^{3}\left[\rho_{l}-\rho_{g}\right] \rho_{l}\right) / \eta_{l}\right)$. Here $\rho_{l}$ is the liquid density, $\rho_{g}$ that of the gas, $D$ is the pipe diameter, $\sigma$ the surface tension and $\eta_{l}$ the liquid viscosity. Their equation has 13 empirical constants. It has been shown, by Viana et al. (2003) and Azzopardi et al. (2013a), to give accurate values of $F r$ for viscosities up to $300 \mathrm{~Pa}$ s. The above work was for bubbles rising in stagnant liquids. When there is finite gas and liquid flow rates, the Taylor bubble velocity is determined from an additive equation whose two terms are due to the bulk motion and to the drift velocity (that which would occur in stagnant liquids). This can be written as

$u_{B}=C_{0}\left(u_{g s}+u_{l s}\right)+K F r \sqrt{g D}$ 
With $u_{g s}, u_{l s}$ being the gas and liquid superficial velocities respectively. Nicklin et al. (1962) reported a value of 1.2 for $C_{0}$ but noted that higher values were more appropriate as the flow rates diminished. Subsequently, this has been addressed by Collins et al. (1978), Dukler and Fabre (1994) and Guet et al. (2004). A more complicated expression was proposed for $C_{0}$ as given by equation (2),

$C_{0}=\frac{C_{B C}}{\left[1+\left(\frac{R \varepsilon_{m}}{R \varepsilon_{c}}\right)^{2}\right]}+\frac{C_{0, R e=\infty}}{\left[1+\left(\frac{R \varepsilon_{c}}{R \varepsilon_{m}}\right)^{2}\right]}$

Values of $C_{B C}=5$ or $2.27, R e_{c}=4000$ and $C_{0, R e=\infty}=1.2$. In this $R e_{m}$ is defined as $\rho_{l}\left(u_{g s}+u_{l s}\right) D / \eta_{l}$.

Hills (1975) and Hills and Darton (1976) noted that the velocities of larger bubbles were higher if they were travelling through a swarm of small bubbles rather than just liquid. They worked on large (square cross-section) columns and pipes where the large bubbles were of the spherical cap type. However, they also studied Taylor bubbles. In their air/water experiments they created bubbly flow of known void fraction and then released a large volume of gas. The velocity of the Taylor bubble was seen to increase as the bubbly void fraction increased. Similar results were obtained by Azzopardi et al. (2014b) who created slug flow in a $67 \mathrm{~mm}$ diameter, vertical pipe operated with air/water at zero liquid flow rate. The flow consisted of a series of Taylor bubbles interspersed with liquid slugs containing small bubbles. Again the velocity of the Taylor bubbles increased as the void fraction in the liquid slug increased. This data is illustrated in Fig. 1 together with data from Hills and Darton (1976) taken on a $50 \mathrm{~mm}$ diameter pipe (the closed symbols). Both set appear to lie on one curve. Hills and Darton proposed that the presence of small bubbles altered the shape of the large bubble making it more pointed which would increase its velocity. It might be considered that the correction to the equation for the Taylor bubble velocity should be applied to the second term. To quantify this effect the data of Azzopardi et al. (2014b) has be recast in the form of the correction factor, $K\left(=\left[u_{B}-\right.\right.$ $\left.C_{0} u_{m}\right] / F r \sqrt{ }[g D]$ ). This is plotted in Fig. 1 (open symbols and is seen to increase as 1 - void 
fraction in the liquid slug increases. A power law regression fit yields

$K=\frac{0.905}{\left(1-s_{g s}\right)^{8.95}}$

Some confirmation of this relationship has been seen in the air/silicone oil data of Azzopardi et al. (2010).

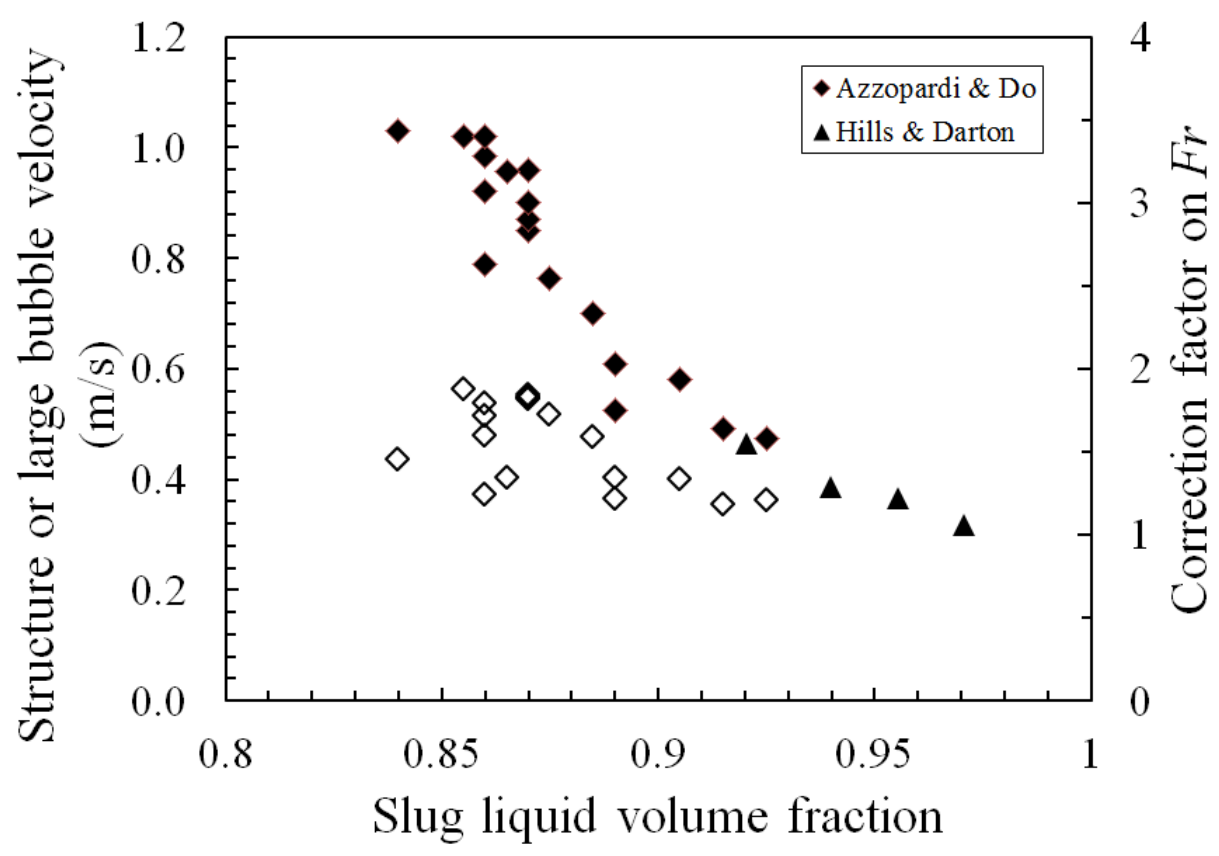

Fig. 1: Effect of small bubble in the liquid of velocity of Taylor bubbles. Closed symbols large bubble velocity; open symbol, $\diamond$ - correction factor $K$ in equation (1). Data from Azzopardi et al. (2014b) and Hills and Darton (1986).

This paper reports experiments on air/silicone oil flow through a sudden contraction mounted either vertically or at $5^{\circ}$ upward from the horizontal. Electrical Capacitance Tomography (ECT) was employed to measure void fraction variation in time. Though the instrument can give cross-section resolved information, it is mainly the time series of cross-sectionally averaged void fraction that has been interrogated to yield characteristics of information of the (mainly slug) flows.

\section{Experimental arrangements}

\section{$2.1 \quad$ Flow facility}


The experimental rig and resources used in this study are the same as that used in Szelinski et al. (2010) except that a sudden contraction was added towards the end the test pipe and that the test pipe was positioned either vertically or at $5^{\circ}$ upward from the horizontal. The point at which the sudden contraction was located was selected so that a more developed flow would be observed just before the gas-liquid flow comes to the contraction. The ranges of the gas and liquid superficial velocities employed were chosen in order to produce bubble and slug flow patterns. The objective of this is to observe the flow characteristics before the sudden contraction, and how it is affected by that change in diameter. The fluids used in this study are air and silicone oil $\left(\right.$ density $=915 \mathrm{~kg} / \mathrm{m}^{3}$; viscosity $=0.005 \mathrm{~Pa} \mathrm{~s}$; surface tension $\left.=0.02 \mathrm{~N} / \mathrm{m}\right)$. Fig.2 shows a schematic representation of the test rig that consists of: an inclinable $6 \mathrm{~m}$ long rigid steel frame on which the test pipe with a sudden contraction is mounted; liquid storage tank; pumps; flow meters; regulating valves; the test section and a separator. In this case the pipe was mounted vertically and the upward gas-liquid directional flow is tested. The oil temperature was monitored. For the vertical experiments, the mean was $18.3^{\circ} \mathrm{C}$ with a standard deviation of $1.7^{\circ} \mathrm{C}$. For the inclined ones the corresponding values were 26.8 and $2.8^{\circ} \mathrm{C}$ respectively. 

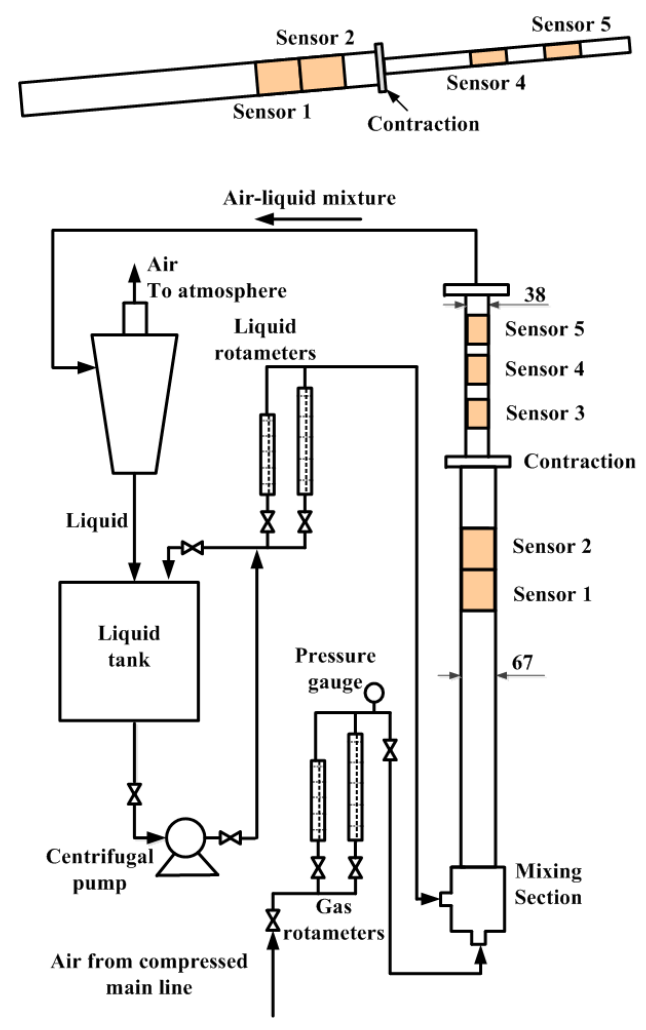

Fig. 2: Schematic of Test Rig

The tests were carried out by taking liquid from the storage tank and pumping it through a bank of variable area flow meters, to monitor flow rates, and into the mixer. Air from the main laboratory, 6 bar compressed air-system was monitored by one of the bank of variable area flow meters and combined with the liquid in the mixer). The mixer consists of an annular section into which the liquid was introduced. The air merges into this annulus through a series of $6 \mathrm{~mm}$ holes on the wall of the capped central pipe. The mixer was mounted at the bottom of the test pipe and there is about $5 \mathrm{~m}$ between this and where the test section is located. The pipe outlet is connected to a separator, the air being released to atmosphere and the liquid returned to the storage tank.

The test section consists of a sudden contraction comprising of an upstream pipe of $67 \mathrm{~mm}$ internal diameter and a $38 \mathrm{~mm}$ internal diameter downstream pipe fitted together with flange joints and sealing "O" rings were positioned in between the two flanges. This gives a cross-sectional area contraction ratio $\sigma_{\mathrm{A}}=0.57$ 
The upstream pipe section was made of a transparent plastic (PVC) which enables the flow to be observed. The downstream pipe, on which the two downstream planes of the Electrical Capacitance Tomography electrodes were mounted, was made from standard UPVC pipe which was opaque.

\subsection{Instrumentation}

Four ECT sensors rings were employed in these experiments. The first two are positioned 489 (Plane 1) and 400 (Plane 2) mm upstream of the contraction. A moveable one is placed at either 140 (Plane 3) or 220 (Plane 4) mm downstream of the contraction. The final sensor is fixed 520 (Plane 5) $\mathrm{mm}$ downstream of the contraction. All five planes were used in the vertical experiments but only planes $1,2,4,5$ were employed in the inclined runs.

The ECT sensor used in this work was designed and manufactured using photolithography technique on flexible printed circuit board (PCB) by PLT Limited. The ECT is used to collect spatial distribution of a mixture of dielectric materials inside a containment by measuring the electrical capacitances between sets of electrodes placed around its periphery and converting these measurements into an image showing the distribution of permittivity as a pixel based plot or image averaged over a volume whose length is equal to that of the measurement electrodes. The lower sensors are a twin plane arrangement, 8 measurement electrodes with 24 radial guards on either side of them. This set-up is based on an embedded electrode configuration for circular sensors. The distance between the centres of the two planes on the upstream pipe is 89 $\mathrm{mm}$.

The basic working principle of the capacitance measurement is to apply an alternating voltage (Vs) between one electrode and ground and the resulting current which flows between source electrode and the remaining electrodes (detectors) to ground is measured. For eight electrodes there will be $8 \times 7=56$ possible capacitance measurements, but as half of these will be shared 
measurements there will on be 28 distinctive measurements. The measured capacitance is used to produce a sensor sensitivity matrix for the case when the sensor is empty and the matrix is composed of a set of sub matrices which correspond to individual pixels in a rectangular grid which is used to define the section cross-section. The sensor is calibrated by filling the sensor with the lower permittivity material and the individual inter-electrode capacitance is measured, this is repeated for the higher permittivity material.

The combination of the capacitance sensor and a computer system make up the ECT system The results will be obtained using a Tomoflow R5000 ECT flow analysis system. Twin plane sensors with guard electrodes are utilized to create two, axially separate image planes along the flow. At each plane the permittivity distribution of the gas-liquid mixture is displayed as a series of normalized pixel located on a $32 \times 32$ square pixel grid. Image of the multiphase flow is plotted using a color scale from blue (pixel full of low permittivity material) to red (pixel full of high permittivity material) to indicate the normalized pixel permittivity.

For each test run, the ECT obtains hold data at a sampling frequency of $1000 \mathrm{~Hz}$ for 60 seconds. Prior to these experiments, the ECT had been tested against another tomography instrument the Wire Mesh Sensor (WMS) probe developed by HZDR, Germany. Reports of the comparisons have been published by Azzopardi et al. (2010) and Hunt et al. (2010). The showed that two instruments gave the same time and space averaged for each flow condition studied. There were also close similarities between the time traces of cross-sectionally averaged void fraction. Were there were differences these could be logically explained.

During the present experiments, as only two planes could be measured simultaneously, measurements were made with every possible pair of planes. This means that for any one plane 
there were repeat runs. These sets of extra information have been used to check the consistency of the measurements. Fig. 3 illustrates how the value of at any set of flow rates is the same in the first and repeat tests.

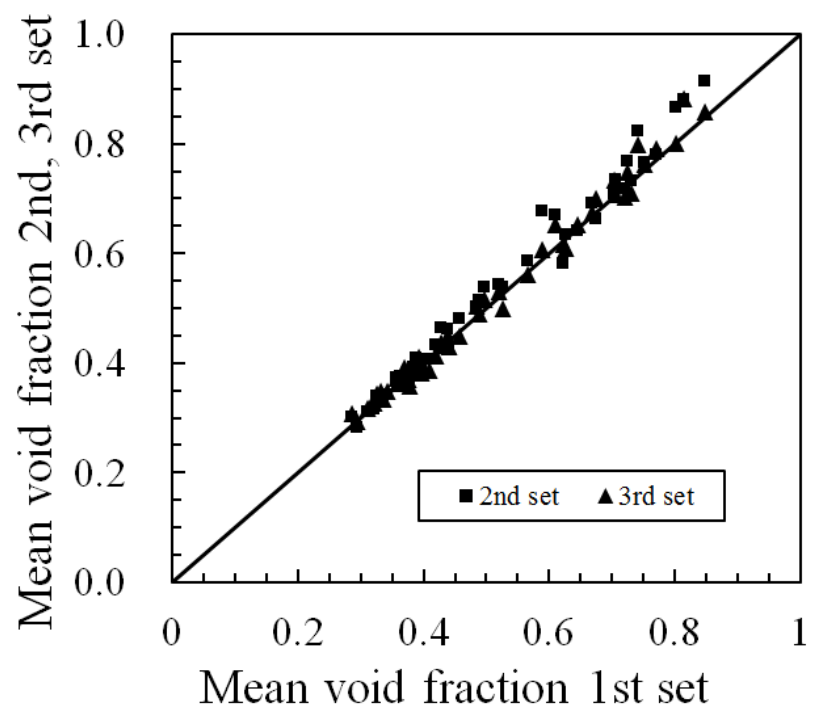

Fig. 3: Consistency of measurements

\subsection{Methodology of data analysis}

In the analysis of the data obtained using the flow facility/instrumentation described above, Probability Density Functions, Power Spectral Density, Cross-correlation and the approach developed by Khatib and Richardson (1984) for extracting the lengths of the liqud slug and Tayor bubble regions were employed. These are presented here.

The distribution of how frequently each value of void fraction occurs in a time series is termed the Probability Density Function (PDF). This is particularly useful because, as shown by, amongst others, Costigan and Whalley (1996), these have different characteristics for each flow pattern: in vertical pipes bubbly flow has a single sharp peak at low void fraction; slug flow is epitomised by two peaks, one at low void fraction being the liquid slug and one at 
higher void fraction corresponding to the Taylor bubble region; churn flow has a peak at higher void fraction with a tail going down in void fraction.

Frequency characteristics of the times series can be obtained using Power Spectrum analysis. Here, Power Spectrum Densities (PSD) have been obtained by using the Fourier transform of the auto covariance functions. Since the auto covariance function has no phase lag, a discrete cosine transform can be applied.

The auto covariance function of a signal $x(t)$ is given by:

$$
R_{x x}(k \Delta \tau)=\frac{1}{T-\tau} \int_{0}^{T-\tau}[x(t)-\bar{x}] \cdot[x(t+k \Delta \tau)-\bar{x}] d t ; \tau<T
$$

where $T$ is the sampling duration, $k \Delta \tau$ is the time delay, $\tau$ is the interrogating time delay and $\bar{x}=\frac{1}{T} \int_{0}^{T} x(t) d t$

The Power Spectrum Density is then obtained from:

$$
P_{x x}(f)=\Delta \tau\left(\frac{1}{2} R_{x x}(0)+\sum_{k=1}^{\tau / \Delta \tau-1} R_{x x}(k \Delta \tau) m(k \Delta \tau) \cos (2 \pi f k \Delta \tau)\right)
$$

where $w(k \Delta \tau)$ is a windowing function. Windowing functions help to suppress the spectrum leakage which mostly comes out as the side lobes at the high frequency end of the spectrum. By using an appropriate windowing function the frequencies contributing to the system becomes clear. In initial analysis carried out here, a basic cosine windowing function was used,

$$
m(k \Delta \tau)=\cos \left(\frac{\pi k \Delta \tau}{2 \cdot \tau}\right)
$$

The velocity of structures can be obtained by cross-correlating two signals obtain from detectors which are positioned at different axial locations. The cross-correlogram is characterised by a 
sharp peak at a time delay corresponding to the transit time of structures between the detectors. Dividing this time into the axial distance between the detectors yields the structure velocity.

As noted above, the PDF of the cross-sectionally averaged times series of void fraction in slug flow is characterised by two peaks. The one at lower void fraction, $\varepsilon_{g s}$, corresponds to the liquid slug. The higher value peak at $\varepsilon_{g T B}$ relates to the Taylor bubble. These void fractions of liquid slugs and Taylor bubbles can be used to extract quantitative information about the lengths of the liquid slugs and the Taylor bubbles. An analysis for this was proposed by Khatib and Richardson (1984), who implicitly assumed that the length of the liquid slugs and Taylor bubbles were constant. Their approach results in an equation which can be rearranged to give the fractional liquid slug length, $F$, explicitly as:

$$
F=\frac{L_{g}}{L_{u}}=\frac{s_{g T B}-\varepsilon_{g}}{s_{g T B^{-}}-s_{g s}}
$$

In this equation, $\varepsilon_{g}$, is the overall average void fraction. The length of the slug unit, $L_{u}$, the sum of the lengths of Taylor bubbles, $L_{T B}$, and of liquid slugs, $L_{s}$, can be obtained from the velocities, $u_{B}$, and frequencies, $f$, of Taylor bubbles, as $L_{u}=u_{B} / f$. This can be combined with equation (7) to give the lengths of the two sub-regions.

\section{Results and discussion}

\subsection{Identification of flow pattern}

A quantitative description of the flow pattern can be obtained from time-series analysis of fluctuating signals of measurements of void fraction by the ECT. The key to such quantification is an appropriate measurement method as well as appropriate methods of time-series analysis of the measured fluctuating void fraction signals. This provides the simplest analysis in the time domain. Typical time traces of cross sectional average void fraction from the upstream pipe in 
the vertical case are shown in Fig. 4, it shows clearly the successive regions of high and low void fractions for bubbly flow with and without spherical cap bubbles.

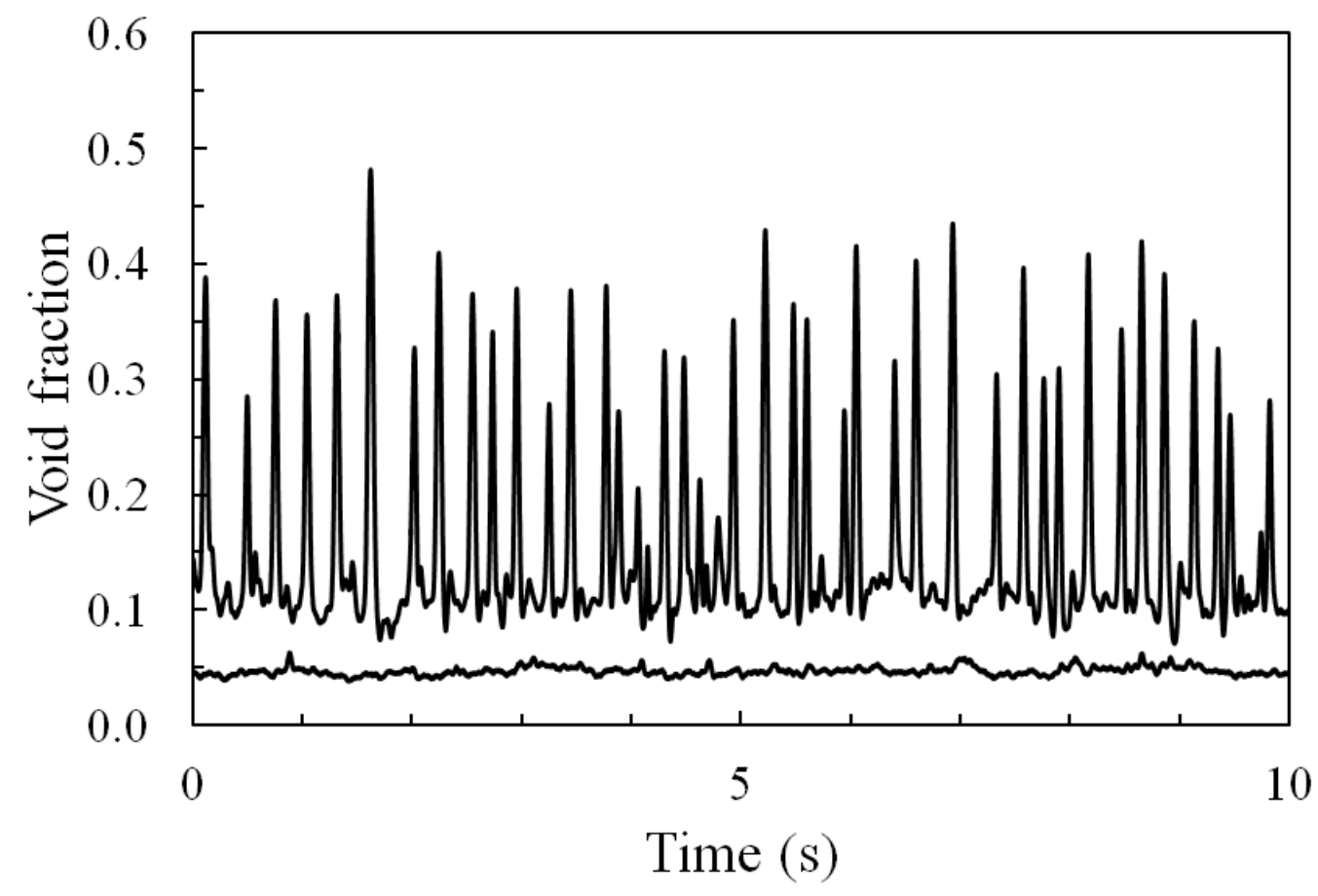

Fig.4: Void fraction times series upstream of the contraction showing signals typical of bubbly and spherical cap bubble flows. Vertical case. Gas superficial velocities $=0.061$ and 0.21 $\mathrm{m} / \mathrm{s}$, respectively. Liquid superficial velocity $=0.52 \mathrm{~m} / \mathrm{s}$.

The PDFs of the void fraction time series illustrated in Fig. 4 are plotted in Fig. 5. For each PDF plot, the approach proposed by Costigan and Whalley (1997) is used to identify the flow pattern for each combination of gas and liquid superficial velocities. At a gas superficial velocity of $0.061 \mathrm{~m} / \mathrm{s}$, the void fraction fluctuates with time but there is no clear structure. The shape of the PDF is characterized by a narrow single peak at a low void fraction (0.05). This single peak at low void fraction is a signature of a discrete bubble flow, i.e., gas bubbles in a liquid continuum. When the gas superficial velocity is increased the time series is characterized by a number of peaks which occur periodically. Visual observation through the transparent pipe wall confirmed that these correspond to large bubbles which do not fill the pipe cross-section totally. Because of their shape they are usually known as spherical cap bubbles. It is noted that these will not be noticeable in smaller diameter pipes as they easily reach the pipe diameter. The PDF for this 
flow is characterised by a slightly shorter peak at a void fraction of 0.11 with a tail extending up to 0.45 .

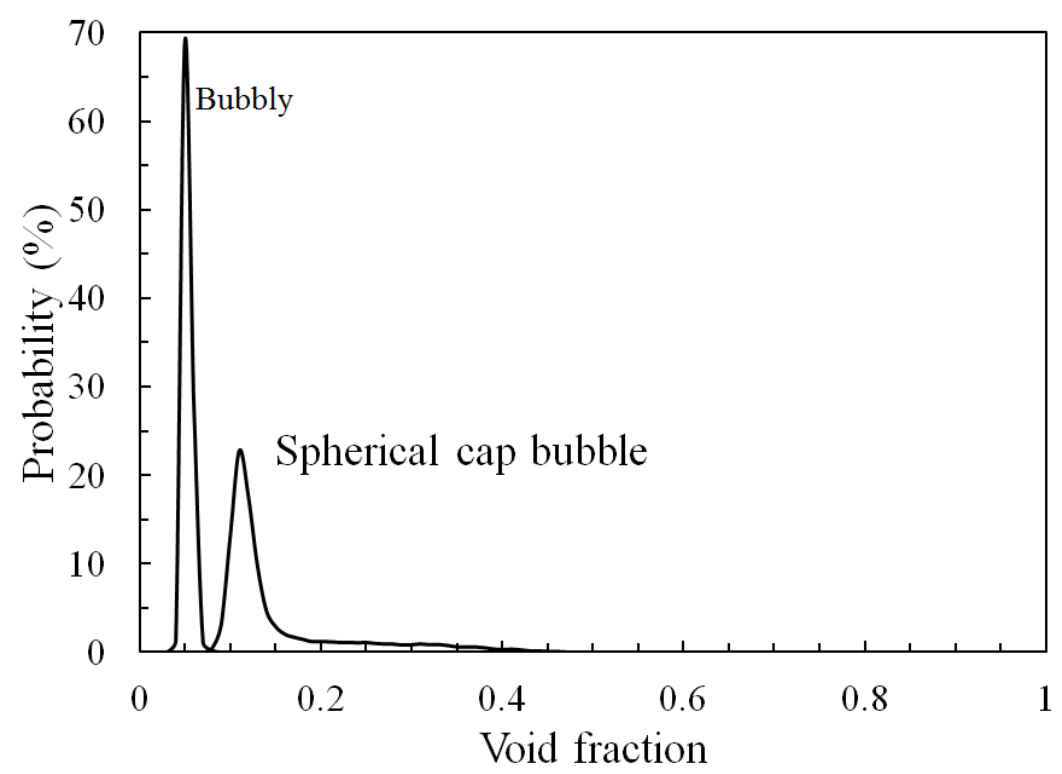

Fig.5: PDFs of void fraction times series illustrated in Fig. 4.

The void fraction time trace for slug flow shows periodic switching between a low void fraction state and a second one at a high value. Examples are shown in Fig. 6 for probes upstream and downstream of the contraction in the vertical case. They have been plotted as void fraction against axial distance to get an impression of the relative length of the two regions upstream and downstream of the contraction. These data correspond to a gas superficial velocity equal to 0.34 $\mathrm{m} / \mathrm{s}$. It is seen that for the high void fraction parts, the large bubbles, which occupy the greater part of the pipe cross-section are usually termed Taylor bubbles, are of limited length ( 2 to 3 pipe diameters in the upstream pipe but much longer ( 20 pipe diameters) in the downstream pipe. The Taylor bubbles are longer in the downstream pipe due to the flow being squeezed into the smaller diameter pipe as well as to having a higher velocity. Slug flow is characterized by a twin peaked PDF, one peak portraying the dispersed bubble flow and the other the annular flow around the Taylor bubble. The PDFs corresponding to the data shown in Fig. 6 are presented in Fig.7 and show two peaks in both the upstream and downstream data, evidence of slug flow and 
Taylor bubbles both upstream and downstream.

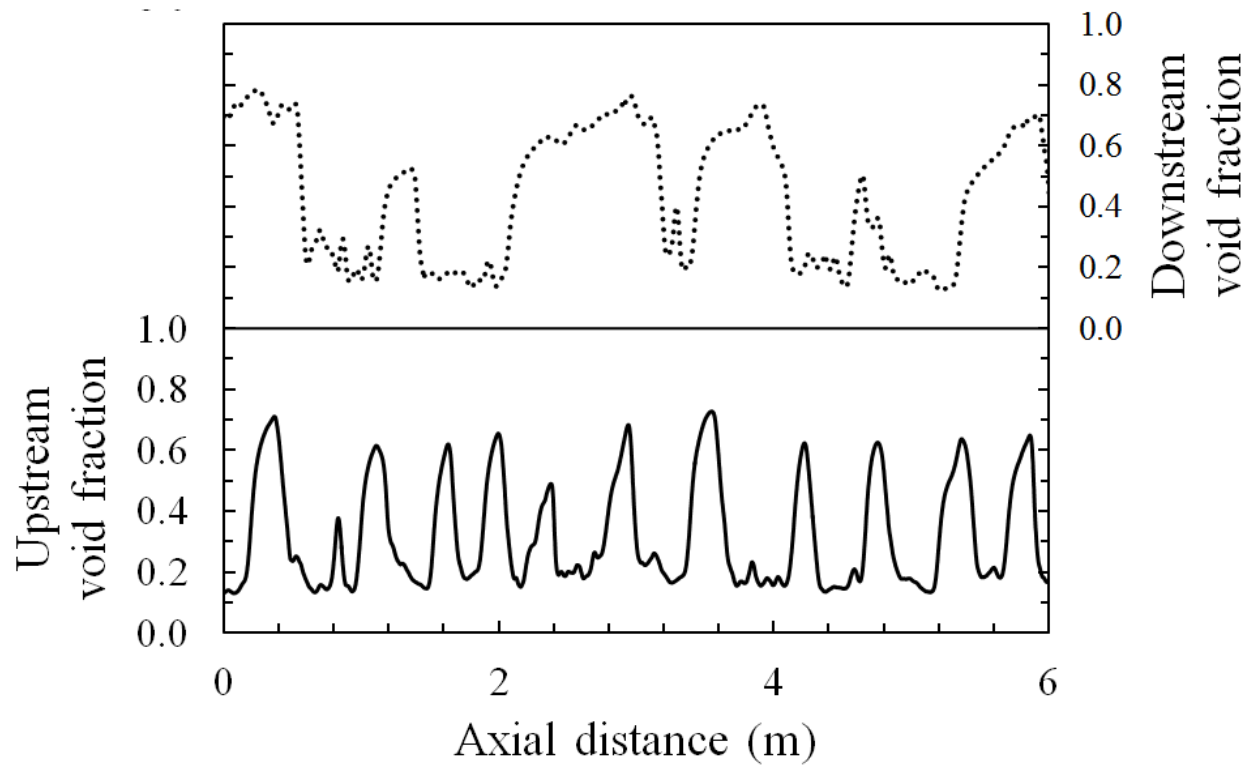

Fig. 6: Void fraction time series plotted against axial distance (obtained by multiplying time by structure velocity. Data from upstream (-) and downstream (.........) of the contraction showing signals typical of slug flow. Vertical case. Upstream gas superficial velocity $=0.34$ $\mathrm{m} / \mathrm{s}$. Upstream liquid superficial velocity $=0.05 \mathrm{~m} / \mathrm{s}$.

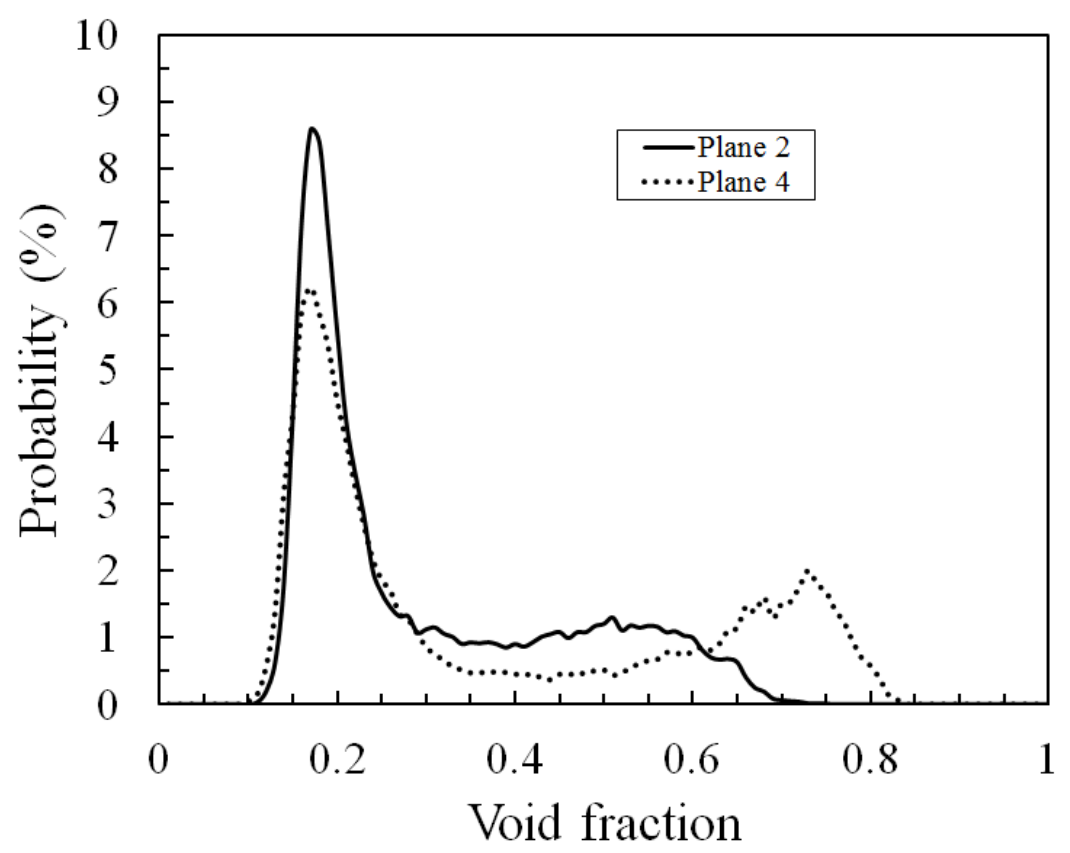

Fig. 7: PDFs of void fraction times series illustrated in Fig. 6.

For the inclined case, the identified flow patterns are slug flow and churn/annular flow. The 
former, as in the vertical case had a PDF with two peaks. The latter had a single peak at high void fraction with a peak towards lower void fraction. Here, an example is shown with slug flow either side of the contraction, Fig. 8. Again, they have been plotted as void fraction against axial distance to get an impression of the relative length of the two regions upstream and downstream of the contraction. It is seen that there is a higher void fraction in the Taylor bubble region in the downstream pipe which corresponds to a thinner liquid film caused by the larger gas velocity. There is also evidence, in the form of increased void fraction at the front of the liquid slug part which indicates an increase of gas entrainment into the slug. The lengths of bubbles and slugs are evidently long, the have been stretched by being forced into the smaller, downstream, pipe.

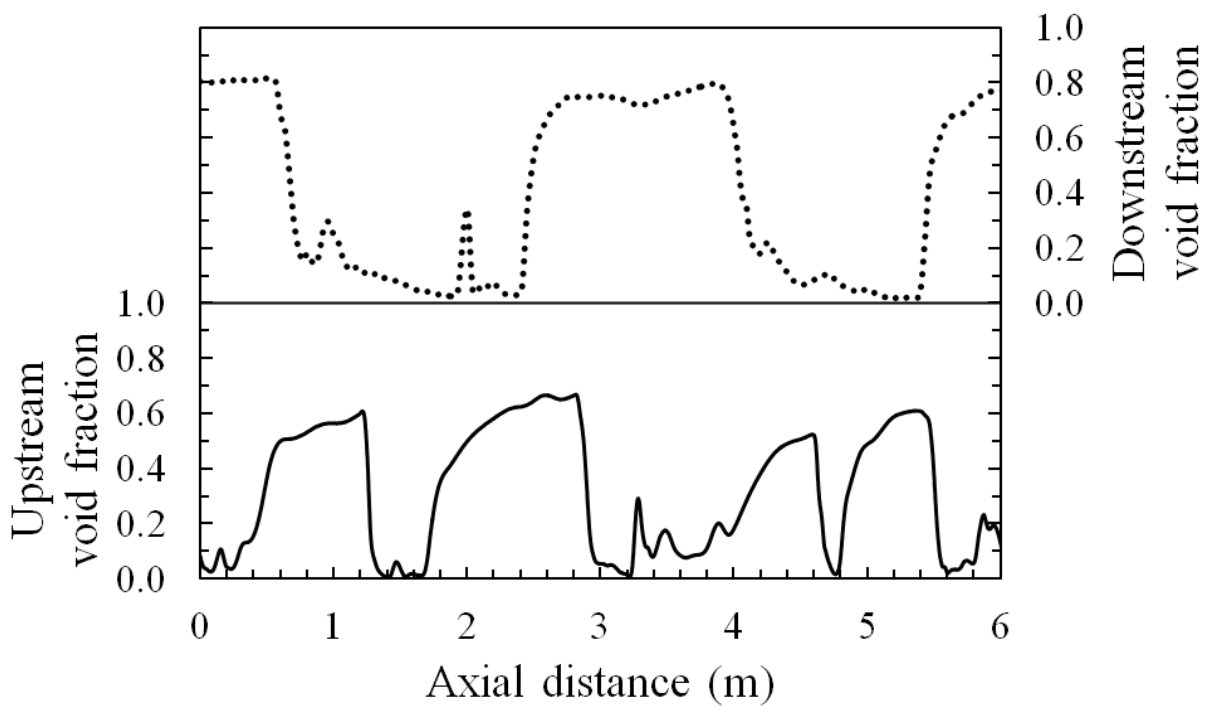

Fig. 8: Void fraction time series plotted against axial distance (obtained by multiplying time by structure velocity). Data from upstream (- and downstream (…….) of the contraction showing signals typical of slug flow. Inclined case. Upstream gas superficial velocity $=0.49$ $\mathrm{m} / \mathrm{s}$. Upstream liquid superficial velocity $=0.24 \mathrm{~m} / \mathrm{s}$.

These observations are reflected in the features of the corresponding PDFs shown in Fig. 9. 


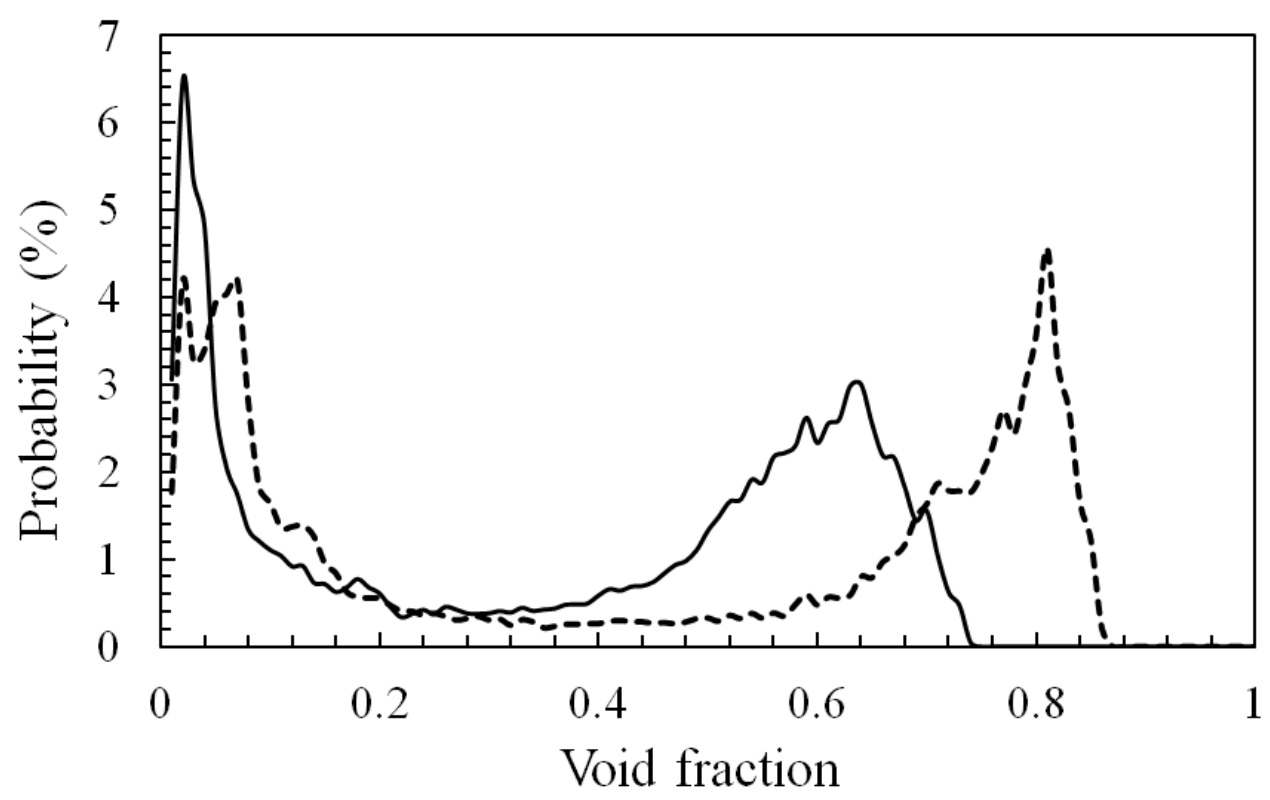

Fig. 9: PDFs of void fraction times series illustrated in Fig.8.

The flow pattern at each pair of flow rates has been identified from the PDF. For the upstream pipe of the vertical case the flow patterns identified were bubbly, spherical cap bubble and slug flow. Although in the middle of each flow pattern areas the PDFs have very obvious shapes, the transition between flow patterns is not so easy to identify just by the shape of the PDF. Between bubbly and spherical cap bubble the criterion is the start of a tail towards higher void fraction. It is supported by the appearance of sharp peaks in the void fraction time traces; these are the spherical cap bubbles. The spherical cap bubble/slug transition was linked to the appearance of a second, higher void fraction, peak in the PDF. This peak can be difficult to spot in some cases and this is why some cases are identified as "transition". In the downstream pipe there were fewer cases of bubbly flow with these occurring at the highest liquid flow rate. The ranges of flows in the spherical cap bubble regime were also more limited as it was easier for them to reach the walls.

The flow patterns identified have been plotted in Figs. 10 and 11 for the upstream and downstream pipes, respectively together with the transition lines of Taitel et al. (1980) for bubble/slug, Jayanti and Hewitt (1992) for slug/churn and Barnea (1986) for churn/annular. The 
bubble slug matches the bubble/spherical cap bubble transition except for the lowest liquid superficial velocity for the upstream pipe. The same hold for the downstream pipe.

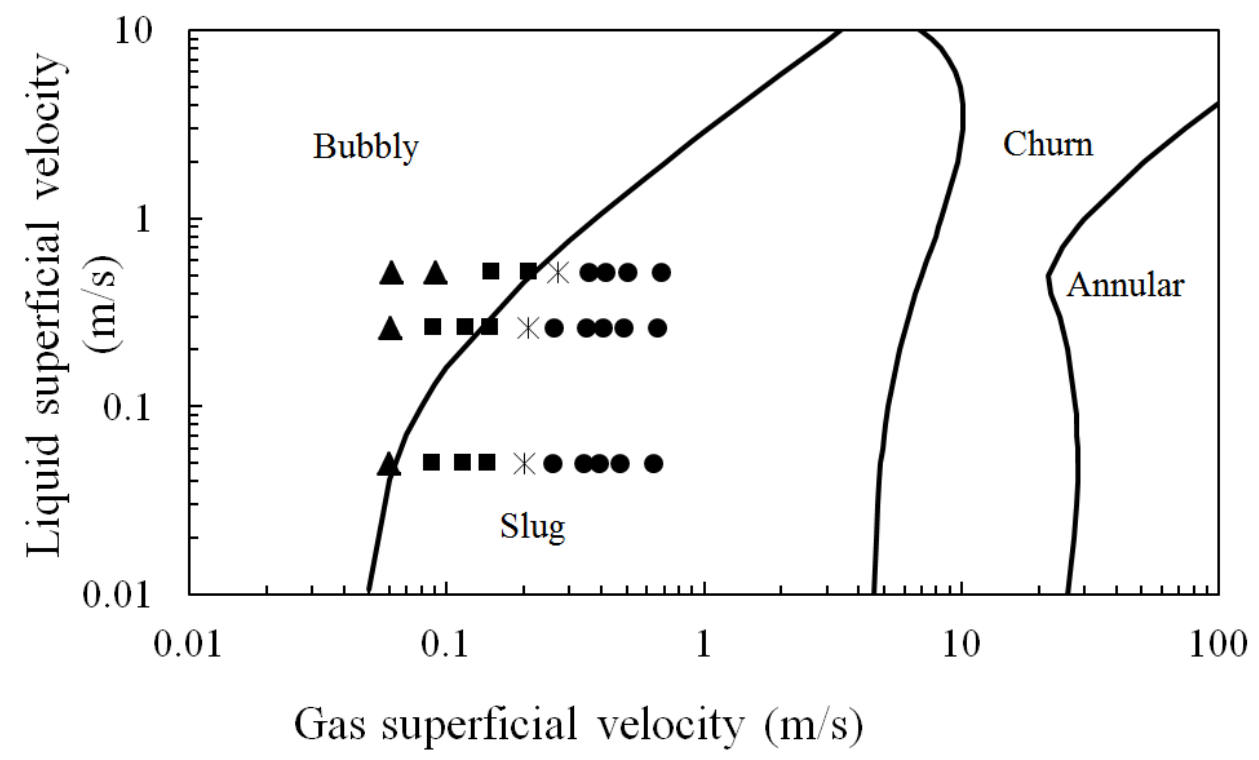

Fig. 10: Flow pattern maps showing the flow patterns determined from PDFs in the present experiments. Vertical case upstream of the contraction. $\mathbf{\Delta}$ Bubbly flow; $\mathbf{~ S p h e r i c a l ~ c a p ~ b u b b l e ; ~}$ * Transition to slug flow; • Slug flow. The bubble to slug line is from Taitel et al. (1980), that for slug to churn is from Jayanti and Hewitt (1992) and that from churn to annular is from Barnea (1986)

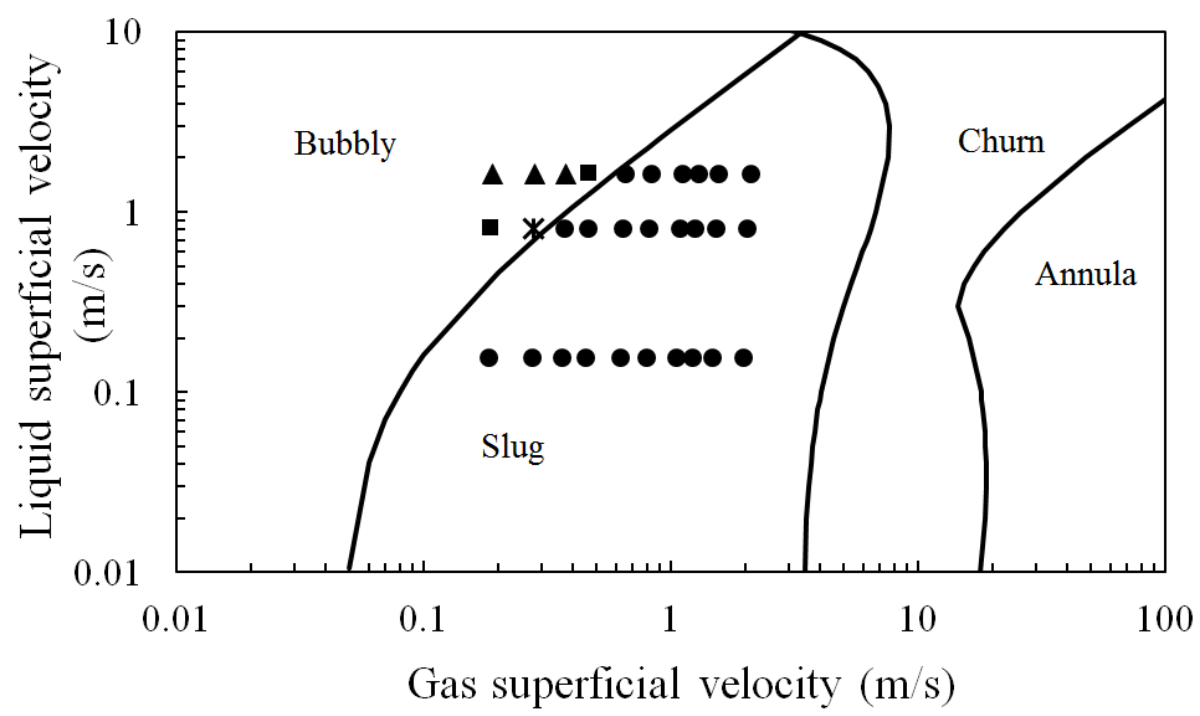

Fig. 11: Flow pattern maps showing the flow patterns determined from PDFs in the present experiments. Vertical case downstream of the contraction. $\Delta$ Bubbly flow; - Spherical cap bubble; * Transition to slug flow; • Slug flow. The bubble to slug line is from Taitel et al. (1980), that for slug to churn is from Jayanti and Hewitt (1992) and that from churn to annular is from Barnea (1986) 
In the inclined case the flow patterns identified are slug and churn/annular. The former, as in the vertical case had PDFs with two peaks whilst for the latter, a single peak at high void fraction with a tail towards lower void fraction. The flow patterns identified are plotted in Figs. 12 and 13 for the upstream and downstream pipes together with the transition lines calculated from the equation of Shoham (2006). For the upstream pipe intermittent (slug)/annular transition is predicted at much higher gas superficial velocities than observed in the experimental result. Much better agreement is seen in the case of the downstream pipe. A possible explanation for the poor agreement in the case of the upstream pipe might lie in the fact that its diameter is larger than those for the experiments which make up the body of knowledge used to develop the models. Moreover, the models were developed on a data base consisting almost uniquely of air/water experiments. The physical properties of the present experiment are significantly different, particularly at a much lower surface tension. Szalinski et al. (2010) presented data for air water and air/silicone oil (the liquid used in the present experiments) in a vertical pipe of the same diameter as the upstream pipe in the present work and found that the void fraction representing the small bubbles in the liquid slug was higher for silicone oil than for water. Their measurements also show that the air/silicone oil flow contains more small bubbles than the air/water flow, whereas the air/water flows forms larger gas structures. It can therefore be argued that the balance between coalescence and break up shifted towards more coalescence in the higher surface tension air/water flow than in air/silicone oil flow with its lower surface tension. 


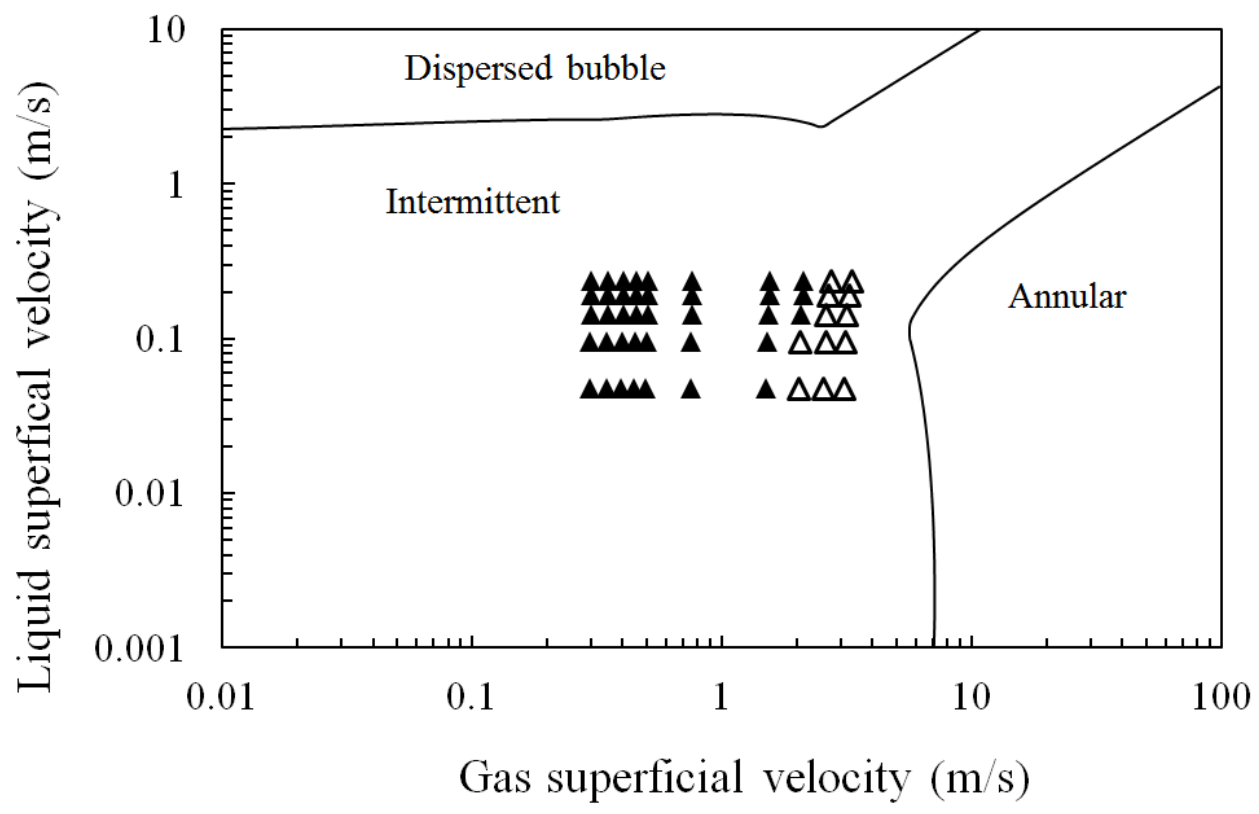

Fig. 12: Flow pattern maps showing the flow patterns determined from PDFs in the present experiments. Inclined case upstream of the contraction. $\Delta$ Slug flow; $\Delta$ Annular flow. The lines are from Shoham (2006)

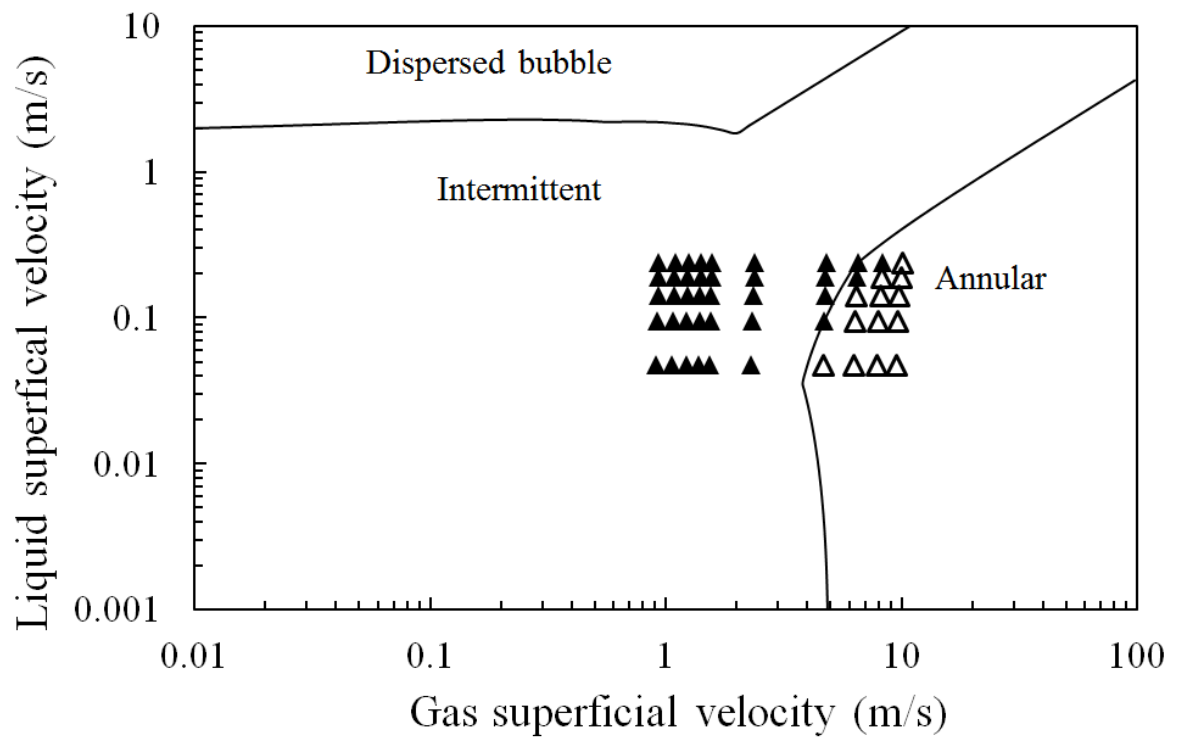

Fig. 13: Flow pattern maps showing the flow patterns determined from PDFs in the present experiments. Inclined case upstream of the contraction. $\Delta$ Slug flow; $\Delta$ Annular flow. The lines are from Shoham (2006)

\subsection{Structure velocities}

The structure velocity, taken to be equal to the Taylor bubble velocity, which was obtained from cross correlating the void fraction times series from probes 1 and 2 and 4 and 5 are shown in Figs. 
14 and 15, respectively, for the vertical experiments. As can be seen there is a noticeable effect of mixture velocity. In addition, the data is differentiated by liquid superficial velocity which is probably caused by the different values of void fraction in the liquid slug at each liquid superficial velocity. Also shown are the predictions of equation (1) with $K=1$ or with the value of $K$ from equation (3). For $K=1$ there is no effect of liquid superficial velocity. However, if $\mathrm{K}$ from equation (3) is employed, the predictions correctly follow the trends of mixture velocity and liquid superficial velocity though not matching the absolute values exactly. Data (both upstream and downstream) from the inclined experiments are shown in Fig. 16. Also shown are the predictions of equation (1) with $C_{0}=1.2$ and $K F r=0.54$. This last value was proposed by Bendiksen (1984). The predictions follow the data well except at the highest mixture velocities which is not surprising as at those velocities the flow has ceased to be slug and is annular as indicated in Figs. 12 and 13.

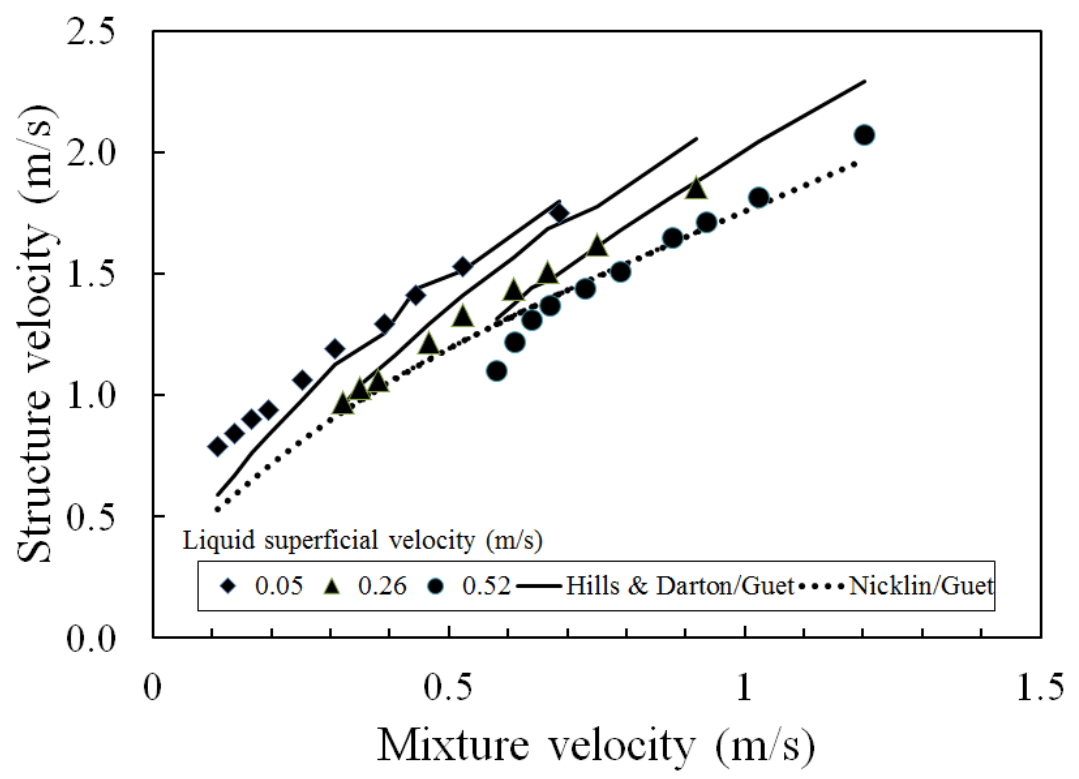

Fig. 14: Effect of mixture velocity and liquid superficial velocity on structure velocity (velocity of Taylor bubble, upstream pipe, vertical case. The three solid line correspond to liquid superficial velocities of $0.05,0.26$ and $0.5 \mathrm{~m} / \mathrm{s}$, respectively from top to bottom 


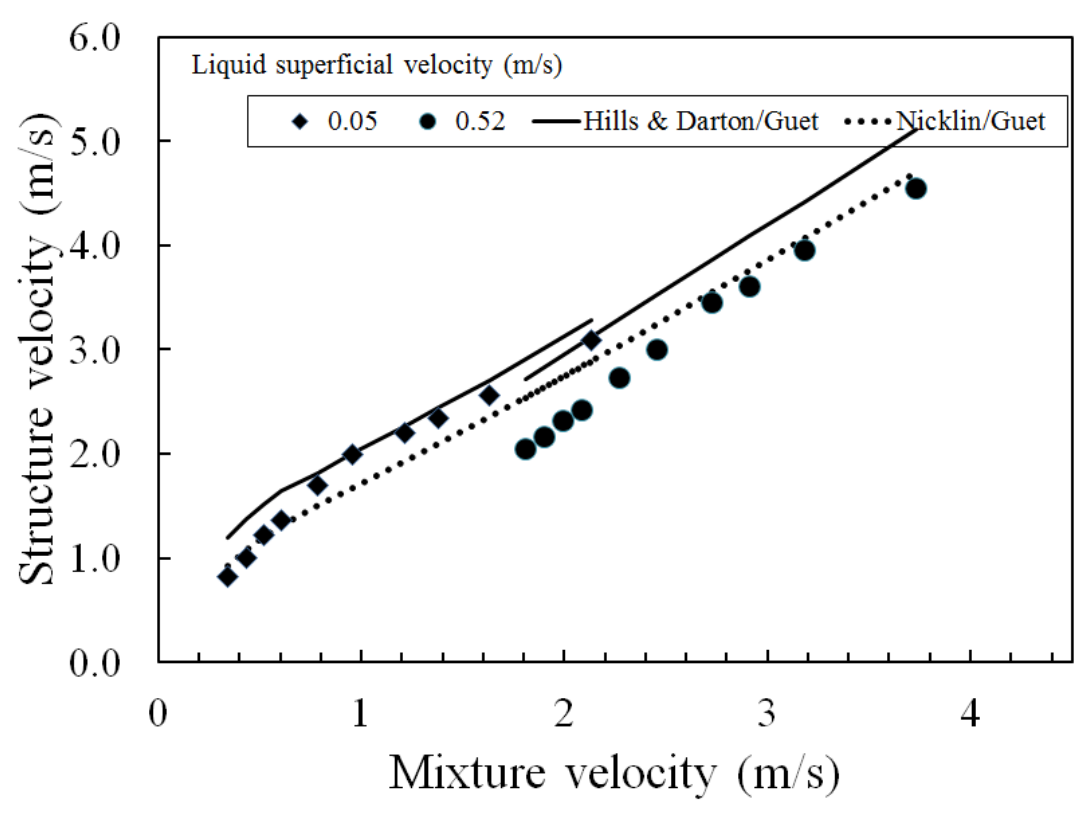

Fig. 15: Effect of mixture velocity and liquid superficial velocity on structure velocity (velocity of Taylor bubble, downstream pipe, vertical case. The two solid line correspond to liquid superficial velocities of 0.05 and $0.5 \mathrm{~m} / \mathrm{s}$, respectively from top to bottom

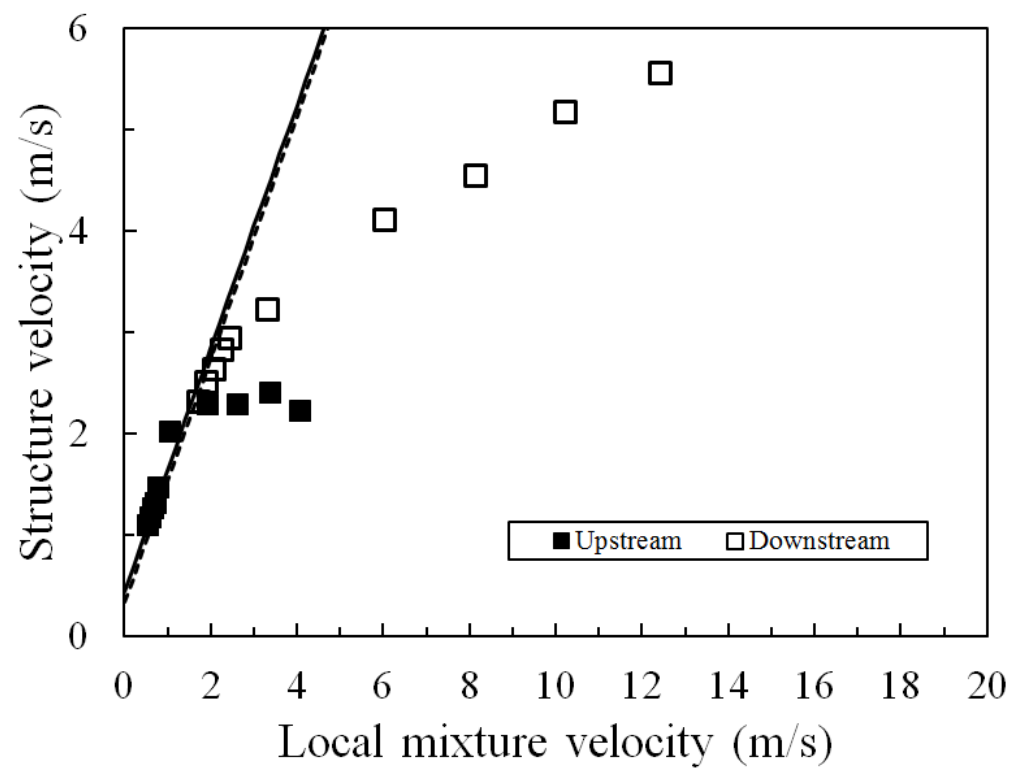

Fig. 16: Experimental obtained structure velocities upstream and downstream of the inclined sudden contraction and prediction of form of equation (1) [—- upstream, - - - - downstream]. Upstream liquid superficial velocity $=0.24 \mathrm{~m} / \mathrm{s}$.

\subsection{Liquid slug and Taylor bubble lengths}

The lengths of liquid slugs and Taylor bubbles have been determined using the method of 
Khatib and Richardson (1984), described above, for both orientations. The results are shown in Figs. 17-20 and show that the lengths increase as the flow passes through the contraction; in most cases the ratio of downstream to upstream value is about 2 to 3 . This supports the idea that the fluids are essentially stretched as they pass into the smaller diameter pipe. The upstream/downstream area ratio is 3.1. Note that there are data downstream when there are none upstream. This results from a change in flow pattern from spherical cap bubble to slug flow. If the spacings between spherical cap bubbles are calculated they are seen to be similar to the lengths of liquid slug at the higher gas flow rates supporting the assumption that spherical cap bubbles grow to become Taylor bubbles in the vertical case.

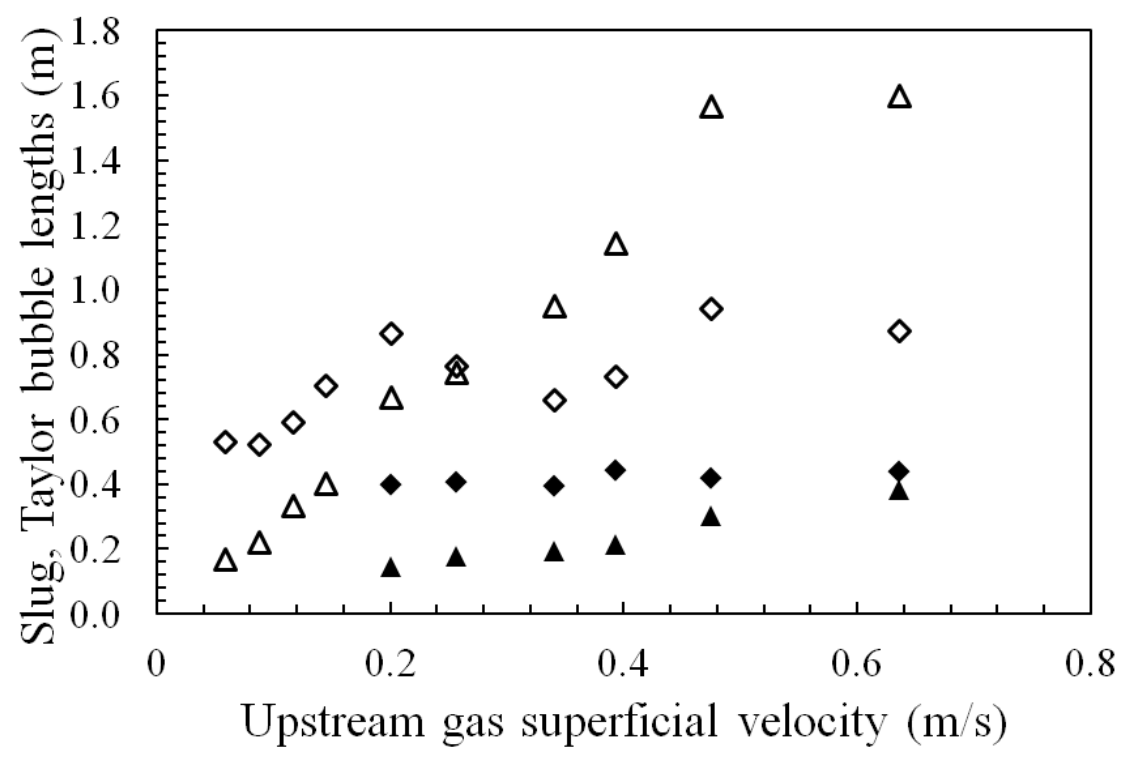

Fig. 17: Changes in lengths of liquid slugs and Taylor bubbles across contraction. Vertical case. Closed symbols - upstream; open symbols - downstream. $\bullet$ Liquid slugs; $\boldsymbol{\Delta}$ Taylor bubbles. Upstream liquid superficial velocity $=0.05 \mathrm{~m} / \mathrm{s}$. 


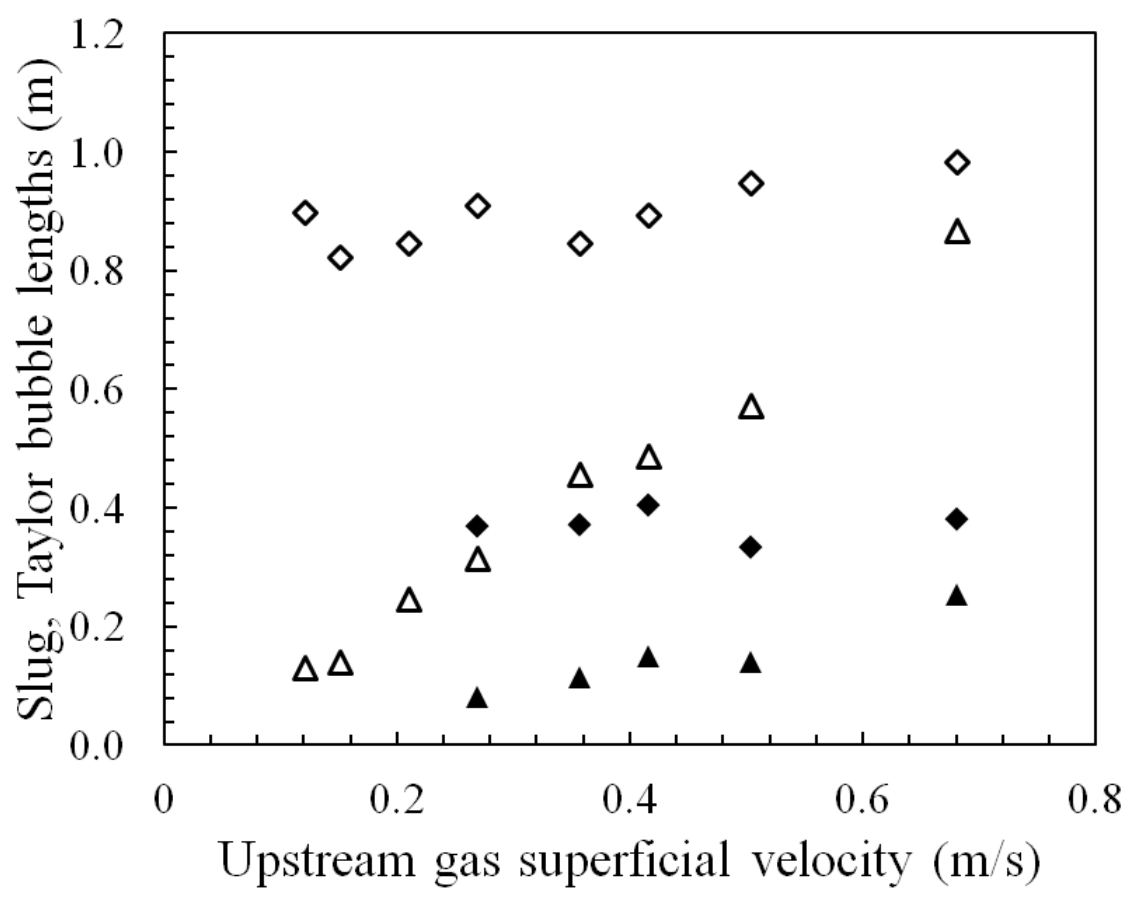

Fig. 18: Changes in lengths of liquid slugs and Taylor bubbles across contraction. Vertical case. Closed symbols - upstream; open symbols - downstream. $\bullet$ Liquid slugs; $\boldsymbol{\Delta}$ Taylor bubbles. Upstream liquid superficial velocity $=0.52 \mathrm{~m} / \mathrm{s}$.

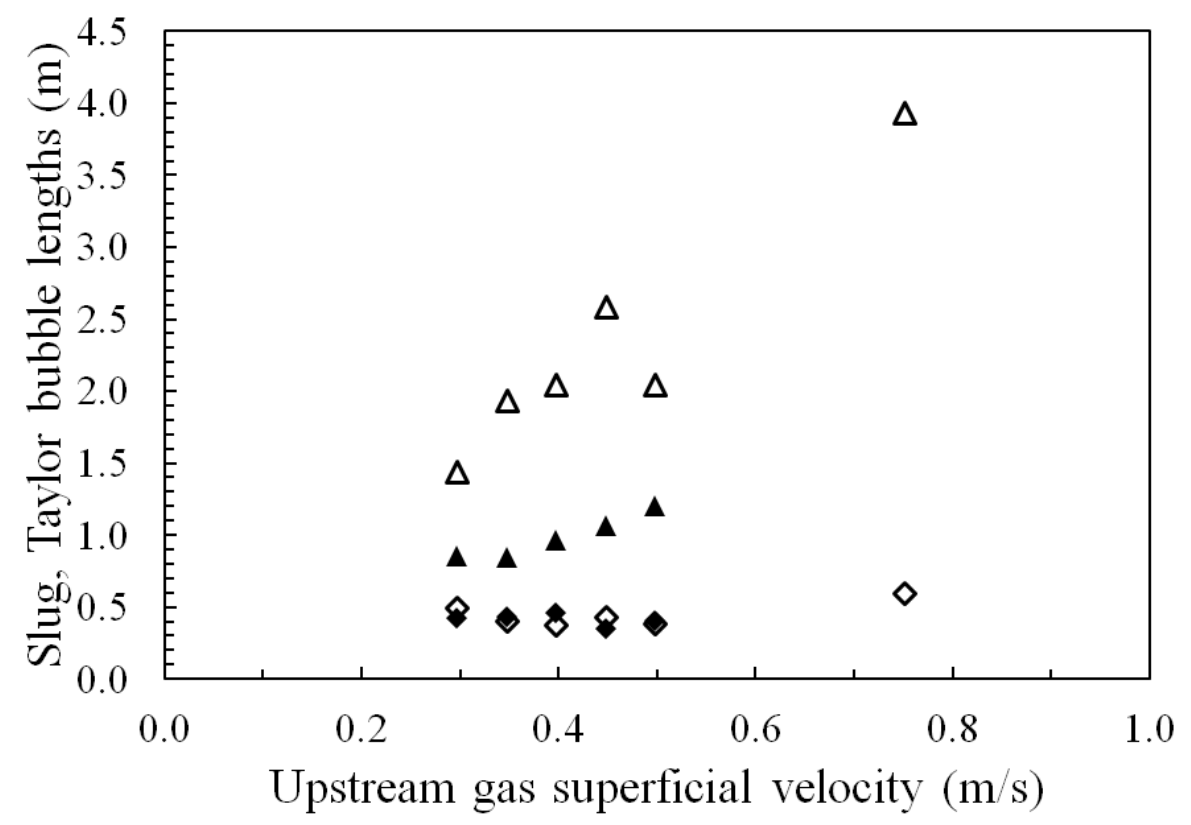

Fig. 19: Changes in lengths of liquid slugs and Taylor bubbles across contraction. Inclined case. Closed symbols - upstream; open symbols - downstream. $\bullet$ Liquid slugs; $\boldsymbol{\Delta}$ Taylor bubbles. Upstream liquid superficial velocity $=0.05 \mathrm{~m} / \mathrm{s}$. 


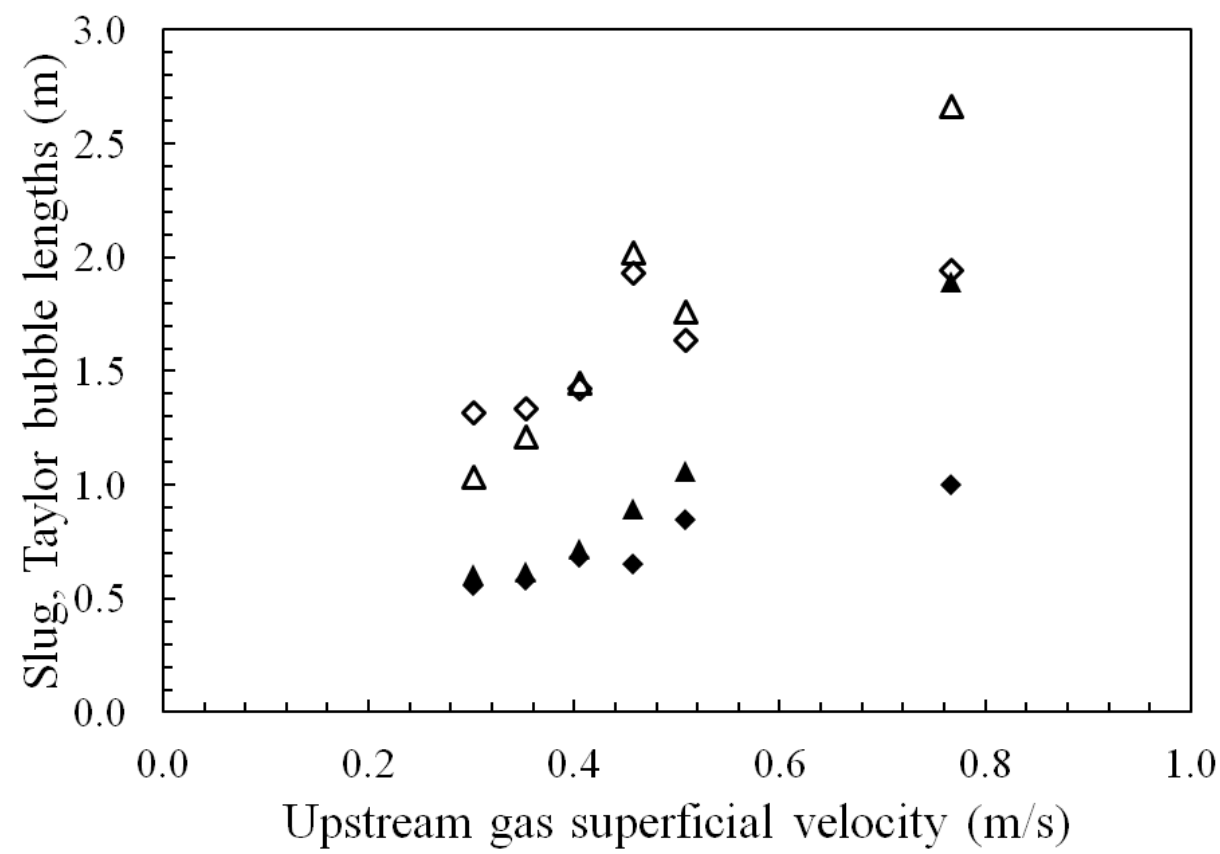

Fig. 20: Changes in lengths of liquid slugs and Taylor bubbles across contraction. Inclined case. Closed symbols - upstream; open symbols - downstream. $\bullet$ Liquid slugs; $\boldsymbol{\Delta}$ Taylor bubbles. Upstream liquid superficial velocity $=0.24 \mathrm{~m} / \mathrm{s}$.

\subsection{Frequencies}

If the frequencies of the slugs, obtained using the PSD approach described above, are examined it is noted that for many of the flow rates considered here there is very little change across the contraction. This is illustrated in Fig. 21 which shows data from both the vertical and inclined cases. The values for the inclined cases are lower than the vertical ones. This follows the results of Abdulkareem et al. (2013) who shows how, for the same flow rates, the frequency increase as the orientation of the pipe approaches the vertical. Now there is certain logic about this lack of change of frequency across the contraction. Other variables describing slug flow such as lengths, velocities do change because of stretching etc. However, to change the frequency would require a major, axial remixing of the flow or a change in flow pattern across the contraction. If the latter does not occur, liquid slugs and Taylor bubbles follow each other in through the contraction without any change in frequency. 


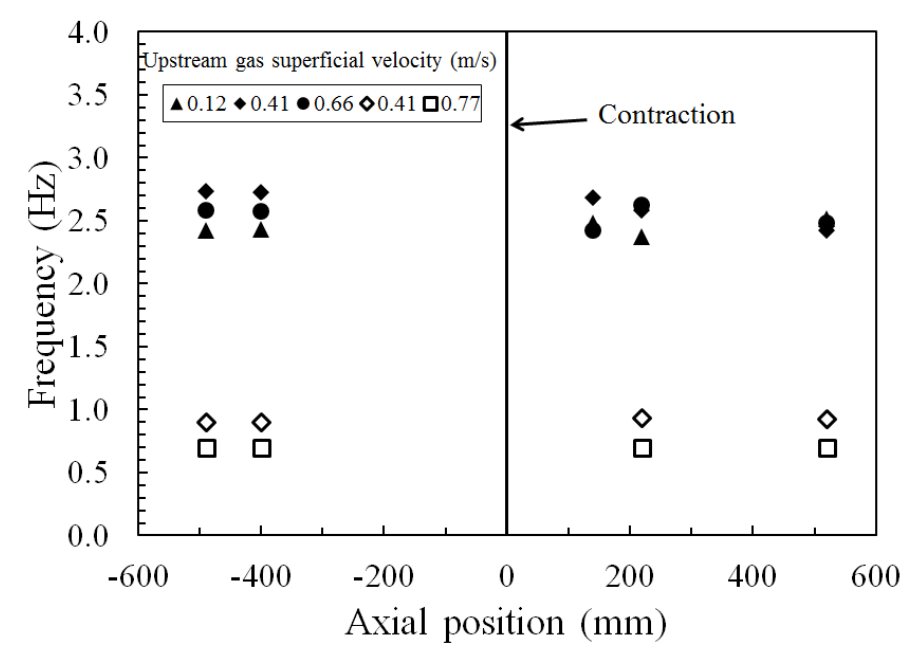

Fig. 21: Lack of effect of axial position across the contraction. Closed symbols - vertical case; open symbols - inclined case.

\subsection{Other examples of persistence of frequency}

Examination of the literature shows that the results of persistence of frequency across a change in geometry, such as a contraction or a bend with pipes of different orientation on either side of it, are not confined to the present results. Here, examples are provided to support the wider applicability of this occurrence. The first is from the work of Legius et al. (1997) who employed a vertical facility consisting of $7 \mathrm{~m}$ of $80 \mathrm{~mm}$ pipe with a contraction (included angle $=60^{\circ}$ ) and $10 \mathrm{~m}$ of $50 \mathrm{~mm}$ pipe above it. They reported the frequencies obtained by analyzing the output of a pressure transducer mount on the wall of the $50 \mathrm{~mm}$ pipe. They did not report any measurements from the upstream pipe. So that persistence of frequency has to be inferred. Now, it has been found that frequencies from different flow rates and pipe diameters are very well grouped if plotted as a gas based Strouhal number $\left(f D / u_{g s}\right)$ against the Lockhart-Martinelli parameter $\sqrt{ }\left[(d p / d z)_{l} /(d p / d z)_{g}\right]$, where $\mathrm{dp} / \mathrm{dz}$ is the frictional pressure gradient for each phase flowing alone in the pipe. Note, it is equal, to a reasonable approximation to $\rho_{l} u_{l s}{ }^{2} / \rho_{g} u_{g s}{ }^{2}$. Fig. 22 shows that data from a number of sources are grouped together implying a good correlation. If the data of Legius et al. for the $50 \mathrm{~mm}$ pipe is plotted using these dimensionless groups, it is seen to lie below all the other data. The Strouhal numbers have been recalculated employing the 
downstream frequencies together with the upstream diameter and upstream velocities. The revised data lie in the midst of all the other data. This implies no change in frequency across the contraction and so gives indirect support to the idea of persistence of frequency.

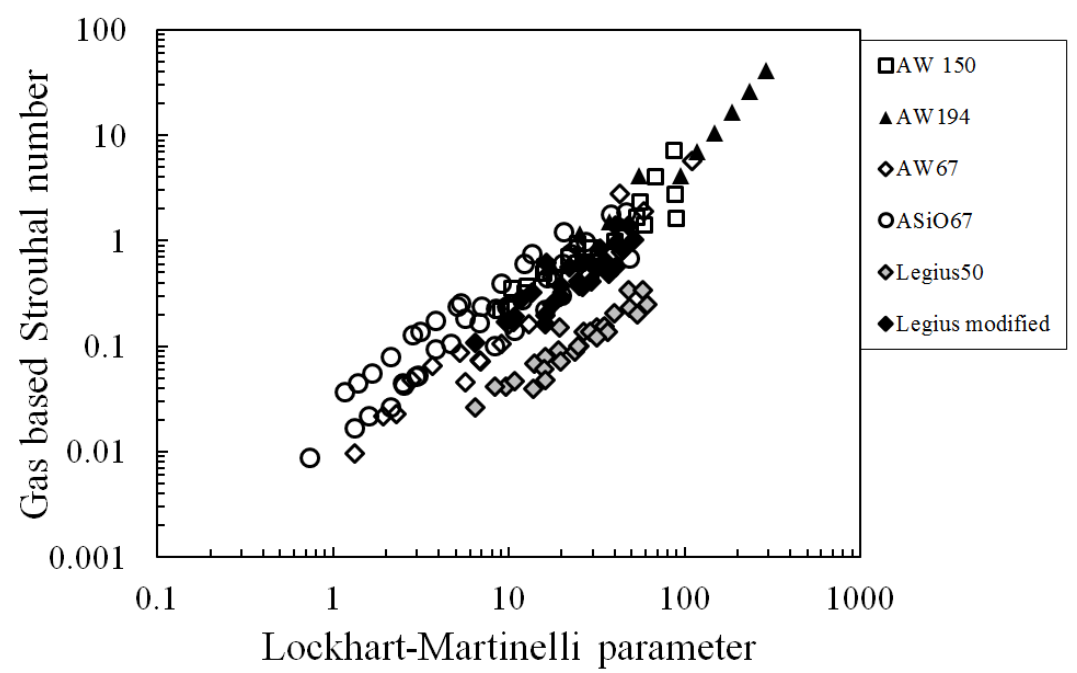

Fig. 22: Plot of dimensionless frequency based on gas superficial velocity against Lockhart Martinelli parameter for vertical pipes. A150 - $150 \mathrm{~mm}$ air/water - Cheng et al. (1998); AW194 - 194 mm air/water - Lucas (2002); AW67 67 mm air/water - Hernandez Perez et al. (2010); ASiO67 - $67 \mathrm{~mm}$ air/silicone oil - Szalinski et al. (2010); Legius $50 \mathrm{~mm}$ - based on downstream pipe - Legius et al. (1997); Legius modified - based on frequency from downstream pipe and diameter and superficial velocities from upstream pipe.

Another geometry where the upstream and downstream frequencies can be examined is the Venturi. Geraci et al. $(2007,2014)$ measured film thickness time series at several points about the circumference upstream and at the throat of a Venturi though which air and water were flowing in the annular flow pattern. The Venturi studied had an upstream diameter of $38 \mathrm{~mm}$, a $32^{\circ}$ convergence angle, a $19 \mathrm{~mm}$ diameter throat and a $4^{\circ}$ diffuser angle returning it to a $38 \mathrm{~mm}$ diameter. It was positioned at inclinations of $0^{\circ}, 30^{\circ}, 45^{\circ}, 60^{\circ}$ and $85^{\circ}$ from horizontal. Geraci et al. (2007) reported data from a $38 \mathrm{~mm}$ diameter pipe, equivalent to just upstream of the Venturi whilst Geraci et al. (2014) provide data from the throat of the Venturi. Here data from the horizontal case are compared with data from horizontal pipes of similar diameters. In this case, as the flow was annular, the frequency was made dimensionless using the liquid superficial 
velocity. Flow this flow pattern the plot has a negative slope. As can be seen in Fig. 23, all the data except that from the Venturi throat are reasonable correlated on this plot, the throat data lies below the band of data. However, as with the Legius et al. data, if the information is recast so that the throat frequency is combined with the upstream diameter and superficial velocities, the modified data lie along the data band. This can be interpreted as waves from upstream of the convergence retaining their frequency as they pass into the throat.

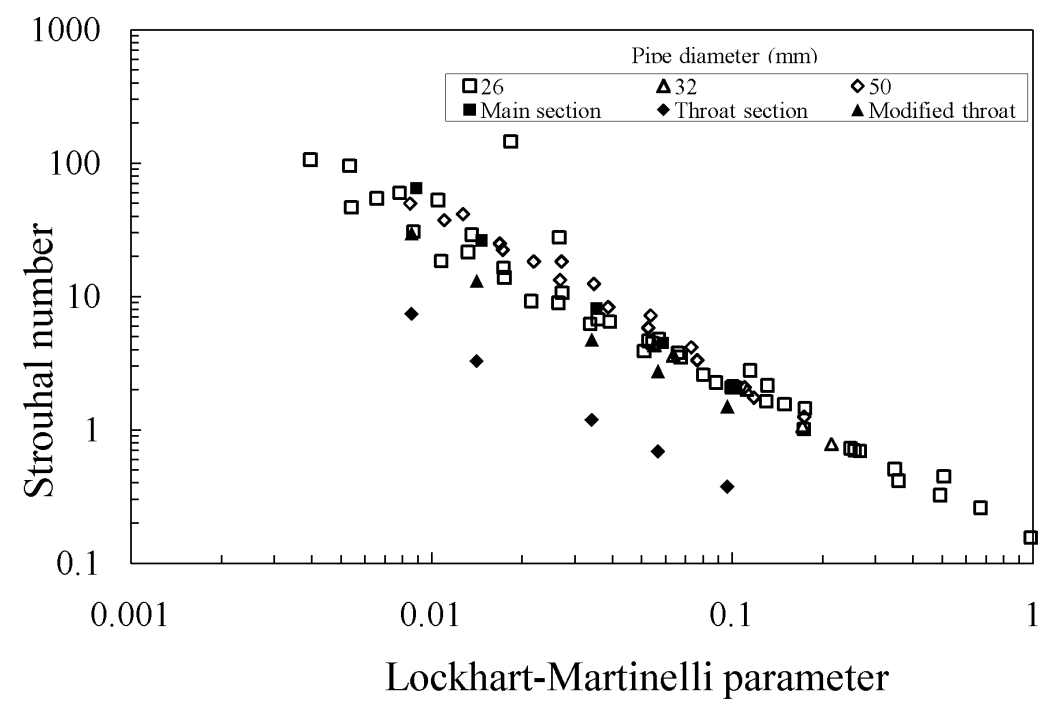

Fig. 23: Plot of dimensionless frequency based on gas superficial velocity against Lockhart Martinelli parameter for horizontal pipes and Venturis. $26 \mathrm{~mm}$ - Fukano et al. (1983);32 mm Jayanti et al. (1990); $50 \mathrm{~mm}$ - Paras and Karabelas (1991); main section - 38 mm diameter Geraci et al. (2007); throat, modified throat - Geraci et al. (2014)..

The other geometry from which data is available is a horizontal pipe, $90^{\circ}$ bend, vertical riser combination. The work of Saidj et al. (2014) was mentioned in the Introduction. They used 34 mm diameter pipes. Fig. 24 shows data from their experiments, but not published in their paper, of frequencies against axial position. The majority of the data show the frequency being the same before and after the bend, evidence of persistence of frequency. 


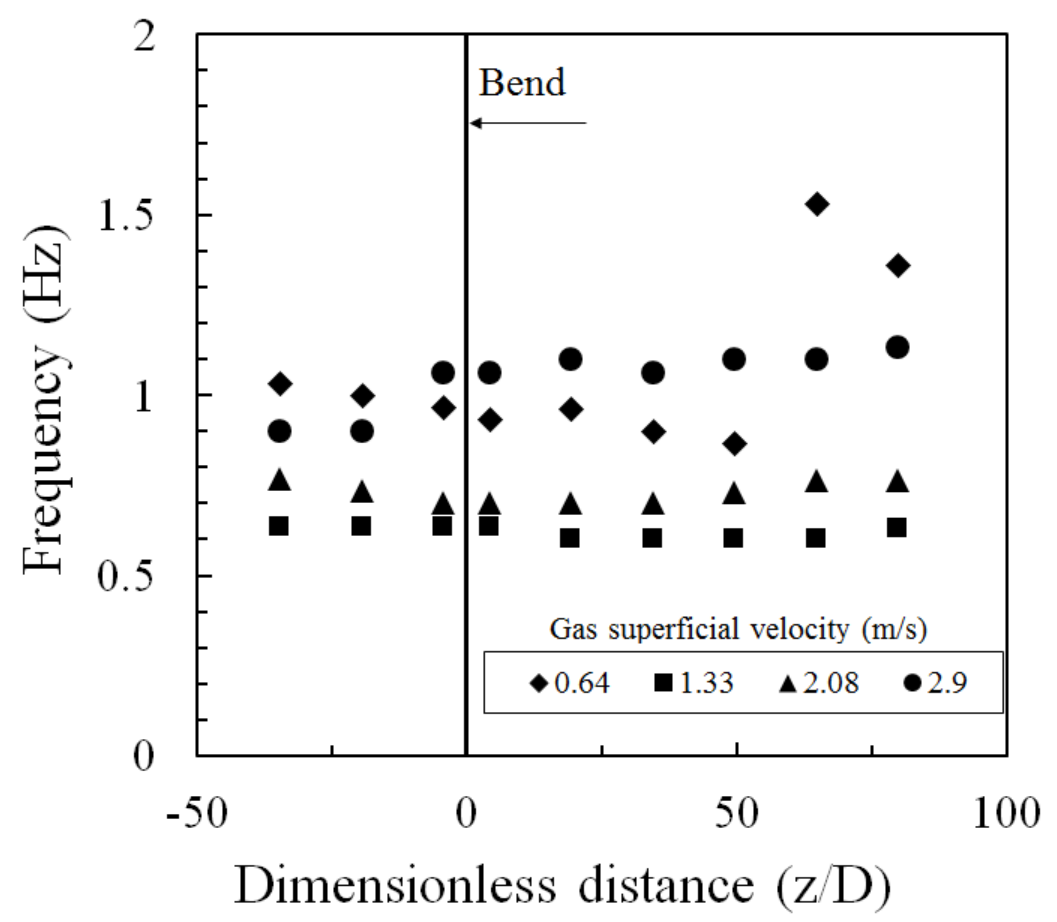

Fig. 24: Frequency along the horizontal and vertical pipes either side of the $90^{\circ}$ bend. Pipe diameter $-34 \mathrm{~mm}$, liquid superficial velocity $-0.81 \mathrm{~m} / \mathrm{s}$. Experiments of Saidj et al. (2013).

Now the majority of the work discussed has been for air/water in smaller diameter pipes. The present work has used silicone oil as the liquid. This has a viscosity ( $5 \mathrm{mPa}$ s) slightly higher than water and a surface tension more typical of industrial fluids $(0.02 \mathrm{~N} / \mathrm{m})$. The upstream pipe was $67 \mathrm{~mm}$, getting towards industrial scale. For the last example we can examine the data presented by Azzopardi et al, (2014c). This consists of a $189 \mathrm{~mm}$ pipeline several hundred meters long, a $90^{\circ}$ bend and a $50 \mathrm{~m}$ riser. Gamma densitometers were mounted upstream of the bend and at three levels up the riser. Slug flow initiated in the pipeline continued up the riser. Analysis of the time series data yields slug frequencies. Fig. 25 shows that the frequency is essentially constant across the bend. This provides more evidence of persistence of frequency. 


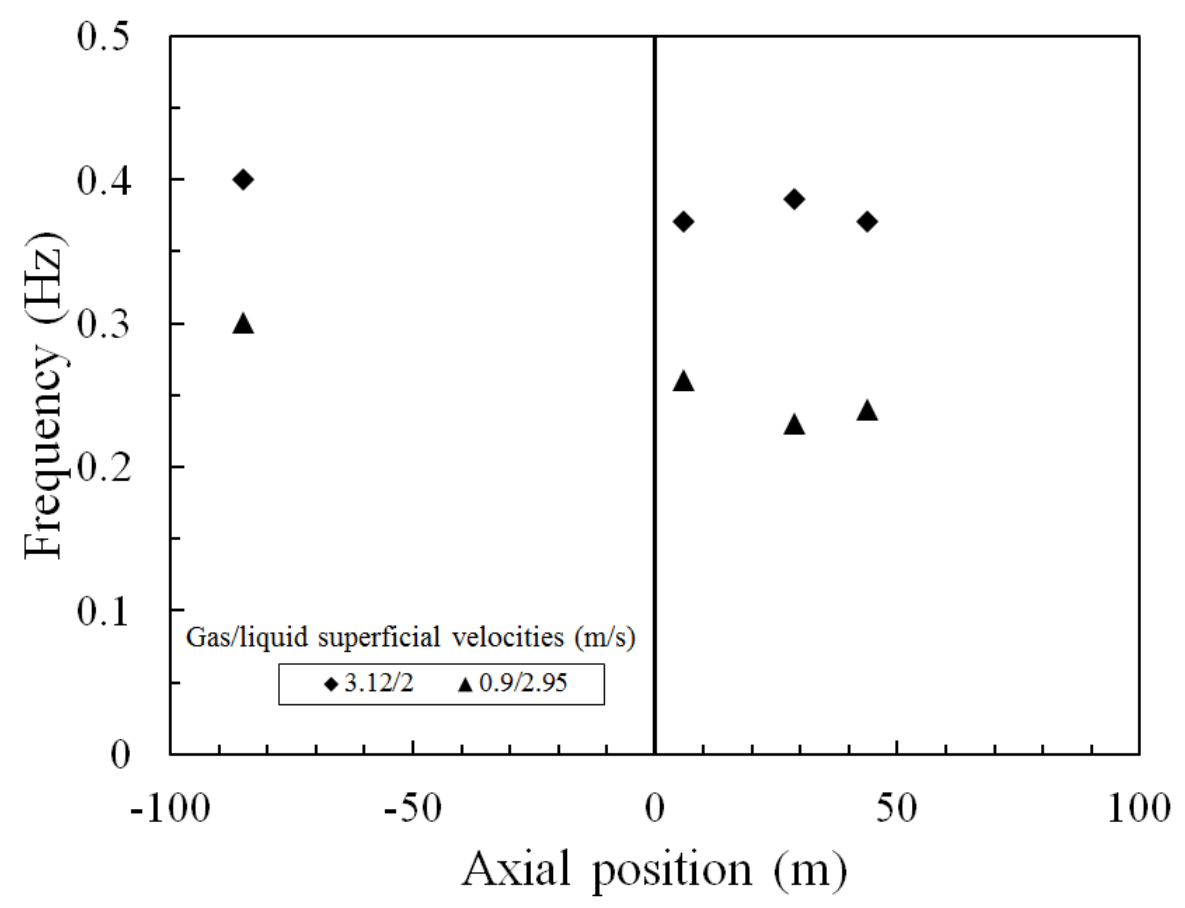

Fig. 25: Frequency along the horizontal and vertical pipes either side of the $90^{\circ}$ bend. Pipe diameter - $189 \mathrm{~mm}$, pressure - $20 \mathrm{bar}$ - nitrogen/naphtha, Azzopardi et al. (2014c).

\section{Conclusions}

From the measurements presented here of the behavior of periodic structures across sudden contractions the following can be concluded:

- The velocities and length of the slug and Taylor bubble units are both increased as the flow passes into the smaller diameter pipe. This is seen for both vertical and inclined orientations.

- In contrast, the frequency of slug does not vary across the contraction. This is taken as evidence that the flow has persistence or memory.

- Evidence has been found in the literature that this persistence of frequency occurs in other geometries, i.e., gradual contraction, Venturi, and the horizontal pipe, $90^{\circ}$ bend and vertical riser combination.

- In addition to these, it has been seen that the slug/Taylor bubble velocities are affected by the smaller bubbles in the liquid slug preceding it. A correction factor based on the 
measurements of Hills and Darton (1976) has been shown to predict trends correctly.

\section{Acknowledgements}

L.A. Abdulkareem would like to thank the University of Zakho and the Ministry of Higher Education, Kurdistan Regional Government for support during his PhD studies. A. Azzi would like to thank EPSRC for a Visiting Research Fellowship under Grant number EP/E004644/01. M. Abdulkadir would like to express sincere appreciation to the Nigerian government through the Petroleum Technology Development Fund (PTDF) for providing the funding for his doctoral studies.

This work has been in conjunction with the Joint Project on Transient Multiphase Flows and Flow Assurance. The Authors wish to acknowledge the contributions made to the work by discussions with members of ASCOMP, GL Noble Denton; BP Exploration; CD adapco; Chevron; ConocoPhillips; ENI; ExxonMobil; FEESA; FMC Technologies; IFP Energies nouvelles; Granherne; Institutt for Energiteknikk; Kongsberg Oil \& Gas Technologies; MSi Kenny; PDVSA (INTEVEP); Petrobras; PETRONAS; SPT Group; Shell; SINTEF; Statoil and TOTAL.

\section{References}

Abdulkareem, L.A., Azzopardi, B.J., Hunt, A., 2013. Tomographic investigation of gas-oil flow in inclined pipes. International Conference on Multiphase Flow (ICMF-2013), Jeju, South Korea.Paper \#221.

Attou A., Bolle L., 1999. A model for pressure drop of gas-liquid bubbly flow through an orifice or an abrupt pipe contraction. Chemical Engineering and Technology 22, 589-599.

Azzopardi, B.J., 2006. Gas-liquid flows, Begell House Incorporated, New York.

Azzopardi, B.J., Abdulkareem, L.A., Zhao, D., Thiele, S., da Silva, J.M., Beyer, M., Hunt, A., 2010. Comparison between Electrical Capacitance Tomography and Wire Mesh Sensor output for air/silicone oil flow in a vertical pipe. Industrial and Engineering Chemistry Research 49, 8805-8811.

Azzopardi, B.J., Pioli, L., Abdulkareem, L.A. 2014a. The properties of large bubbles rising in very viscous liquids in vertical conduits. Submitted to International Journal of Multiphase Flow.

Azzopardi, B.J., Do, H.K., Azzi, A., Hernandez Perez, V., 2014b. Characteristics of air/water slug flow in an intermediate diameter pipe. Submitted to Experimental Thermal and Fluid Science.

Azzopardi, B.J., Kjølaas, J., Azzi, A., Hewakandamby, B., 2014c. Gas-liquid flow development up a high-pressure vertical riser preceded by a pipeline and a $90^{\circ}$ bend. Submitted to A.I.Ch.E. Journal.

Barnea, D., 1986. Transition from annular flow and from dispersed bubble flow-unified models for the whole range of pipe inclinations. International Journal of Multiphase Flow12, 733-744.

Bendiksen, K.H., 1984. An experimental investigation of the motion of long bubbles in inclined tubes, International Journal of Multiphase Flow 10, 467-483.

Brennen, C.E., 2005. Fundamentals of Multiphase Flow. Cambridge University Press.

Chen, I.Y., Wongwises, S., Yang, B., Wang, C., 2010. Two-phase flow across small sudden 
expansions and contractions. Heat Transfer Engineering 31, 298-309.

Chisholm, D., 1983. Two-phase Flow in Pipelines and Heat Exchangers, George Godwin, London.

Collier, J.G., Thome, J.R., 1994. Convective boiling and condensation. $3^{\text {rd }}$ ed., Oxford University Press, New York.

Collins, R., Moraes, F.F., Davidson, J.F., Harrison, D., 1978. The motionof a large gas bubble rising though liquid flowing in a tube. Journal of Fluid Mechanics 89, 497-514.

Costigan, G., Whalley, P.B., 1997. Slug flow regime identification from dynamic void fraction measurements in vertical air-water flows. International Journal of Multiphase Flow 23, 263-282.

Davies, R. M., Taylor, G.I. 1950. The mechanics of large bubbles rising through extended liquids and through liquids in tubes. Proceedings of the Royal Society A200, 375-390.

Dukler, A.E., Fabre, J., 1994. Gas liquid slug flow. Multiphase Science and Technology 8, 355-469.

Dumitrescu, D. T., 1943. Stromung an einerluftblaseimsenkrechtenrohr. Zietschrift fur Angewandte Mathematik und Mechanik, 23,139-149.

Fossa, M., Guglielmini, G., 2002. Pressure drop and void fraction profiles during horizontal flow through thin and thick orifices. Experimental Thermal and Fluid Science 26, 513-523.

Fossa, M., Guglielmini, G., Marchitto, A., 2006. Two-phase flow structure close to orifice contractions during horizontal intermittent flows. International Communications in Heat and Mass Transfer 33, 698-708.

Geraci, G., Azzopardi, B.J., van Maanen, H.R.E., 2013. Effect of inclination on annular gas/liquid flows through a Venturi. In preparation.

Geraci, G., Azzopardi, B.J., van Maanen, H.R.E., 2007. Inclination effects on circumferential film flow distribution in annular gas/liquid flows. AIChE J. 53, 1144-1150.

Guet, S., Ooms, G., Oliemans, R.V.A.,Mudde, R.F., 2004. Bubble size effect on low liquid input drift-flux parameters. Chemical Engineering Science 59, 3315-3329.

Guglielmini, G. Lorenzi, A., Muzzio, A., Sotgia, G., 1986. Two-phase pressure drops across sudden area contractions - pressure and void fraction profiles. Heat Transfer 86, (Proceedings of the 8th Int. Heat Trans. Conf., San Francisco, 17-22 Aug., C.L. Tien et al. Ed.), Hemisphere 5, 2361-2366.

Hernandez-Perez, V., Azzopardi, B.J., Kaji, R., da Silva, M.J., Beyer, M., Hampel, U., 2010. Wisp-like structures in vertical gas-liquid pipe flow revealed by Wire Mesh Sensor studies. International Journal of Multiphase Flow 36, 908-915.

Hills, J.H., 1975. The rise of a large bubble through a swarm of smaller ones. Transactions of the Institution of Chemical Engineers 53, 224-233.

Hills, J.H., Darton, R.C., 1976. Rising velocity of large bubble in a bubble swarm. Transactions of the Institution of Chemical Engineers 54, 258-264.

Hunt, A., Abdulkareem, L.A., Azzopardi, B.J., 2010. Measurement of Dynamic Properties of Vertical Gas-Liquid Flow.7th International Conference on Multiphase Flow, ICMF 2010, Tampa, Florida, USA, May 30 - June 4.

Jayanti, S., Hewitt, G.F., 1992. Prediction of the slug-to-churn transition in vertical two-phase 
flow. International Journal of Multiphase Flow 18, 847-860.

Khatib, Z., Richardson, J.F., 1984. Vertical co-current flow of air and shear thinning suspensions of kaolin. Chemical Engineering Research and Design 62, 139-154.

Legius, H.J.W.M., Van den Akker, H.E.A., Narumo, T., 1997. Measurements on wave propagation and bubble and slug velocities in concurrent upward two-phase flow. Experimental Thermal and Fluid Science.15, 267-278.

Lucas, D., Krepper, E., Prasser, H., 2005. Development of co-current air-water flow in a vertical pipe. International Journal of Multiphase Flow 31, 1304-1328.

Nicklin, D.J., Wilkes, J.O., Davidson, J.F., 1962. Two-phase flow in vertical tubes. Transactions of the Institution of Chemical Engineers 40, 61-68.

Omebere-Iyari, N.K., Azzopardi, B.J., 2007. Gas/liquid flow in a large riser: effect of upstream configurations. Proceedings of the 13th International Conference on Multiphase Production Technology'07, Edinburgh, UK. 13-15 June (Ed. A.P. Hunt). Pub BHR Group Limited [ISBN: 185598087 7], 5-15.

Radovich, N.A., Moissis, R., 1962. The transition from two-phase bubble flow to slug flow. MIT Report 7-7673-22.

Saidj, F., Kibboua, R., Azzi, A. Ababou, N., Azzopardi, B.J., 2014. Experimental investigations of the effect of a vertical $90^{\circ}$ bend on a two-phase air-water flow. Experimental Thermal and Fluid Science submitted.

Schmidt, J., Friedel, L., 1997. Two-phase flow pressure change across sudden contractions in duct areas. International Journal of Multiphase Flow 23, 283-299.

Shoham, O., 2006. Mechanistic modelling of gas-liquid two-phase flow in pipes, Society of Petroleum Engineers.

Szalinski, L., Abdulkareem, L. A., da Silva, M. J., Thiele, S., Beyer, M., Lucas, D., Hernandez Perez, V., Hampel, U., Azzopardi, B. J., 2010. Comparative study of gas-oil and gas-water two-phase flow in a vertical pipe. Chemical Engineering Science 65, 3836-3848.

Taitel, Y., Barnea, D., Dukler, A.E., 1980. Modeling flow pattern transition for steady upward gas-liquid flow in vertical tubes. AIChE J.26, 345-354.

Viana, F., Pardo, R., Yanez, R., Trallero, J.L., Joseph, D.D., 2003. Universal correlation for the rise velocityof long gas bubbles in round pipes. Journal of Fluid Mechanics. 494, 379-398. 